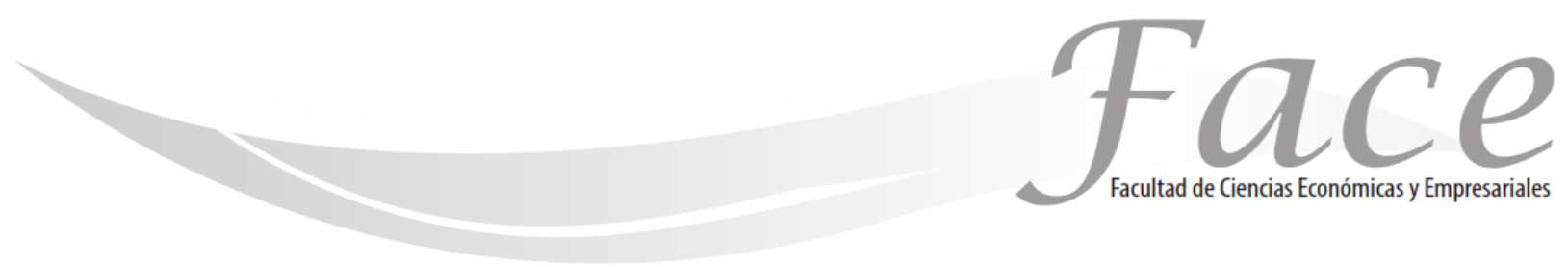

ISSN Impreso: 1794-9920

ISSN Electrónico: 2500-9338

Volumen $16-\mathrm{N}^{\circ} 1$

Año 2016

Págs. 20 - 39

\title{
BAÑOS PÚBLICOS EN BOGOTÁ: UNA APROXIMACIÓN AL PROBLEMA SOCIAL EN LA PROVISIÓN DE BIENES PÚBLICOS
}

\author{
Ruben Darío Diaz Mateus * \\ Enlace ORCID: http://orcid.org/0000-0002-8784-8818 \\ William Fernando Rojas Henao ** \\ Enlace ORCID: http://orcid.org/0000-0001-7495-0314
}

Fecha de Recepción: 25 de Febrero 2016

Fecha de Aprobación: 30 de Mayo 2016

\section{Resumen:}

Este artículo tiene el propósito en determinar la eficiencia social en la prestación del servicio de baños públicos desde la institucionalidad y la responsabilidad en la gestión de bienes públicos en la ciudad de Bogotá; por consiguiente, se realizó revisión de diversas fuentes documentales disponibles en la Empresa Distrital de Servicios Públicos (EDIS), que con el tiempo fue reestructurada y liquidada, y posteriormente creada la institución Instituto Distrital Para La Protección De La Niñez Y La Juventud (IDIPRON). Mediante el método descriptivo, se procede a encuestar a 96 usuarios de los baños públicos del Portal de Transmilenio 170, dado que éste es el punto de mayor afluencia de personas en Bogotá. Los resultados parten en evidenciar la importancia del servicio de baños públicos en la existe una oferta insuficiente y en una infraestructura existente no están distribuidos estratégicamente para la satisfacción del servicio, por tanto, el ciudadano no encuentra un baño público en los lugares donde ejerce sinergias de movilidad generando impactos negativos en la belleza urbana y contaminación ambiental cuyo efecto desencadena en una problemática social de los usuarios (no usuarios) y la entidad gestora de este servicio, evidencia constatada en el código de policía (art. 25, Numeral 10) como una contravención a conductas inapropiadas en sitios públicos; esta coyuntura vulneran el bienestar y derecho colectivo de grupos poblacionales en Bogotá: turistas, trabajadores formales e informales, taxistas, estudiantes, familias, entre otros, quienes se desplazan por la ciudad en el desarrollo de las actividades socioeconómicas.

Palabras Claves: Baños Públicos, Gestión Pública, Eficiencia social, Bien Público, Movilidad.

\footnotetext{
* Docente investigador del Programa de Contaduría Pública y líder del grupo de investigación Desarrollo y Sociedad de la Facultad de Ciencias Administrativas y Contables de la Universidad de La Salle. Economista de la UPTC, Magister en Fundamentos de Economía de la Universidad Santiago de Compostela (España), Maestrante en Desarrollo Sostenible de la Universidad de Manizales; Doctorado en Agrociencias de la Universidad de La Salle (Colombia). Email: rudiaz@unisalle.edu.co

** Administrador de Empresas del Programa de Administración de empresas de la Facultad de Ciencias Administrativas y Contables de la Universidad de La Salle, Investigador, Especialista en Formulación y Evaluación de Proyectos (universidad Católica de Colombia), Empresario e Inversionista Email: william.rojash@gmail.com
} 


\title{
PUBLIC RESTROOMS IN BOGOTA: AN APPROACH TO THE SOCIAL PROBLEM WHEN PROVIDING PUBLIC GOODS
}

\begin{abstract}
:
This article aims to determine the social efficiency in the provision of public goods, from the institutional standpoint, and the responsibility on the public goods management in Bogota city. Hence, we went over information sources available in the "Empresa Distrital de Servicios Públicos" (EDIS), which went through a restructuring and liquidation process. Later on, the institution "Instituto Distrital Para La Protección De La Niñez Y La Juventud" (IDIPRON) emerged to take on the public restrooms service. Applying the descriptive method, 96 people (users of public restrooms) were surveyed in the "Transmilenio portal 170", which is one of the busiest places in the city. The results proved the importance of the public restrooms for the citizens. The current public bathrooms offer is not enough. Besides, the infrastructure is not strategically distributed throughout the city to provide an efficient service. As a result, citizens do not find easily a public restroom around the places where they usually move. The lack of these restrooms leads to negative impacts on the environment and the urban beauty. These effects turn out to be a social issue for the users (not actual users), and the institution in charge of the service. The Police Code (art. 25, Number 10) as a contravention to inappropriate behavior in public places, which violate the welfare population groups such as tourists, formal and informal workers, taxi drivers, students, families, and others whotravel through the city in the development of socio-economic activities.
\end{abstract}

Keywords: Public restrooms, Public Management, Social Efficiency, Public Good, Mobility

\section{BANHEIROS PÚBLICOS EM BOGOTÁ: UMA ABORDAGEM AO PROBLEMA SOCIAL FORNECIMENTO DE BENS PÚBLICOS Resumo:}

Este artigo tem como objetivo verificar a eficiência social no fornecimento de bens públicos, do ponto de vista institucional, ea responsabilidade sobre a gestão de bens públicos na cidade de Bogotá. Por isso, nós fomos sobre fontes de informação disponíveis na "Empresa Distrital de Servicios Públicos" (EDIS), que passou por um processo de reestruturação e de liquidação. Mais tarde, a instituição "Instituto Distrital Pará La Protección De La Niñez Y La Juventud" (IDIPRON) surgiu para assumir 0 serviço de banheiros públicos. Aplicando o método descritivo, 96 pessoas (usuários de banheiros públicos) foram pesquisados no "Transmilenio portal 170", que é um dos lugares mais movimentados da cidade. Os resultados provaram a importância dos banheiros públicos para os cidadãos. A corrente banheiros públicos oferecem não é suficiente. Além disso, a infra-estrutura não é distribuída estrategicamente em toda a cidade para fornecer um serviço eficiente. Como resultado, os cidadãos não encontrar facilmente um banheiro público em torno dos lugares onde eles geralmente se movem. A falta desses banheiros leva a impactos negativos sobre o meio ambiente e a beleza urbana. Estes efeitos vir a ser uma questão social para os usuários (não usuários reais), e a instituição encarregada do serviço. 0 Código de Polícia (art. 25, No. 10) como uma contravenção ao comportamento inadequado em locais públicos, que violam os grupos populacionais de bem-estar, como turistas, trabalhadores formais e informais, taxistas, estudantes, famílias e outros whotravel pela cidade em o desenvolvimento de actividades socio-económicas.

Palavras-Chave: Banheiros públicos, Gestão Pública, eficiência social, bem público, Mobilidade 


\section{INTRODUCCIÓN:}

La provisión de servicios públicos al interior de la sociedad constituye una labor de interés prioritario dentro de los objetivos asociados al bienestar ciudadano de una política pública del Estado; en Bogotá, el Ente Administrativo proporciona de carácter público, privado o mixto bienes públicos. Lo anterior, se fundamentado en la Constitución Política de Colombia de 1991 en el Título XII del Régimen Económico y de Hacienda Pública - Artículo 365, donde "los servicios públicos son inherentes a la finalidad social del Estado. Es deber del Estado asegurar su prestación eficiente a todos los habitantes del territorio nacional (...)" (Congreso de la República, 1991); Por ello, el presente artículo de investigación pretende determinar la eficiencia social en la prestación de bienes públicos por parte del Instituto Distrital para la Protección de la Niñez y la Juventud (IDIPRON) y la responsabilidad distrital del servicio de baños públicos en la ciudad de Bogotá; por consiguiente, se realizó revisión de diversas fuentes documentales disponibles en la Empresa Distrital de Servicios Públicos (EDIS), que con el tiempo fue reestructurada y liquidada, y posteriormente IDIPRON asume las funciones públicas; donde se aplican encuestas y entrevistas a usuarios y colaboradoras del programa de Baños Públicos, así, se contrasta la realidad en la satisfacción de la necesidad básica fisiológica de la comunidad de la ciudad de Bogotá.

El Estado presta otros servicios que aunque no son prioritarios, son fundamentales para el bienestar de los habitantes de la capital. La Administración Distrital está obligada a proveer a los ciudadanos las condiciones necesarias para que gocen de buena salud y tengan un estilo de vida digno. Una de las formas está en garantizar la existencia de baños públicos suficientes para atender la problemática social.

\section{MARCO TEÓRICO:}

El Poder Público es el activo intangible más importante con que cuentan las sociedades democráticas en todo el mundo para reconocer las necesidades básicas; Rodriguez (1980), expone como la estructura del poder público está concentrada en directrices orientadas a satisfacer los intereses de los ciudadanos, buscando bienestar a nivel general, por lo tanto, no debe ser permeado por intereses particulares, al contrario, va encaminado a garantizar el bien común y éxito en la administración de los bienes públicos.
Asegurar la calidad de vida de la población es posible con una gestión pública consciente, igualitaria y transparente, incluidos los principios de la función administrativa mencionados por el Concejo de Bogotá en el artículo 3 del Acuerdo 257 de 20061', norma que al mismo tiempo regula los organismos y entidades Distritales que integran los Sectores de la Organización Central, Descentralizada y de las Localidades. Por ejemplo, la Unidad Ejecutiva de Servicios Públicos UESP, fue transformada en Unidad Administrativa Especial de Servicios Públicos UAESP como una entidad adscrita a la Secretaria del Hábitat. Asimismo, los servidores Públicos Distritales y los particulares que desempeñen funciones Administrativas Distritales, también se acogen a esta norma.

La definición de Administración Pública gira en torno a condiciones disciplinares, según Miguel Duhalt Krauss,"cada Estado debe definir sus propias tareas y por tanto, cada Estado debe elaborar su propia doctrina sobre la Administración Pública". Asimismo, Mosher y Cimmino, citado en (Sánchez, G., p.118, 2001) consideran la Administración Pública no puede ser una ciencia por no tener una base que atribuya valor matemático; no obstante, un pensamiento organizativo estructural por medio de la experiencia y la observación advierte en la ciencia un escenario de la gestión pública es llevada a cabo por un conjunto de organismos, donde la responsabilidad está en la institución ejecutiva para garantizar los derechos individuales y colectivos de la institucionalidad en la vida de cada ciudadano. (De la Encarnación Gabín, 2009). Así, el conjunto de actividades que se llevan a cabo para gestionar un Estado, no son uniformes y tampoco hacen parte de un campo específico, es decir, se suscriben a un plano interdisciplinario que puede llegar a utilizar cualquier rama del conocimiento técnico y científico, en la medida en que la administración gubernamental lo demande (Loaiza Gallón, 2004).

Por otra parte, el bien público es aquel que puede ser consumido o utilizado por todos los individuos de una sociedad y que busca un bien común como lo señala la Constitución Política (Congreso de la República, 1991) en su artículo 1, destacando "(...) la prevalencia del interés general" sobre el particular, por su parte el artículo 63 menciona que estos bienes de uso público son inalienables, imprescriptibles e inembargables. Para Stiglitz (2000), el Bien Público debe cumplir dos condiciones fundamentales: La primera, la no exclusión en su consumo, dado que una persona en la acción de consumir un bien

\footnotetext{
1 Por el cual se dictan normas básicas sobre la estructura, organización y funcionamiento de los organismos y de las entidades de Bogotá, distrito capital, y se expiden otras disposiciones"
} 
público no afecte la posibilidad en el consumo en el total de la población; en segundo lugar, el bien público puede ser utilizado por todos al mismo tiempo y en las mismas condiciones. Parte de este argumento, se evidencia en la crisis socioambiental mundial como consecuencia en la provisión de los bienes púbico, ejemplo de estos sucesos están en las crisis financieras, pobreza extrema, calentamiento global, terrorismo, entre otros, transformando el alcance en el análisis económico donde enfrenta el aumento en la demanda de los mismo, por el efecto globalizador, con ritmos lentos en la prestación de los bienes públicos (González, 2009).

Asimismo, Arnoletto (2007) sostiene que el concepto de Bien Público, es de fondo, diferente al concepto de Bien Común, el primero es el bien o servicio disponible para el uso de todas las personas cuya utilización no restringe ni excluye al resto de la sociedad de su uso; y el bien común proviene de una ideología política del catolicismo, marcado por una directriz de existencia para toda la sociedad que a su vez debe venir acompañada por una serie de valores y principios compartidos en pro del interés general. Por lo anterior, el contexto del objeto de estudio de los baños públicos en Bogotá D.C. está relacionado con los dos conceptos descritos para seguir el concepto de servicios públicos desde la óptica de Diez (1980) y Basavilbaso (1950), donde se define como actividades o prestaciones efectuadas por la Administración Pública en forma directa o indirecta para satisfacer necesidades de interés general 0 colectivo. Por consiguiente, es importante destacar que un servicio empieza a ser considerado como público en el momento en el cual su objetivo esta descrito para atender la necesidad de la sociedad en conjunto (Gordillo, 2013); por ello, el Estado debe garantizar a todos sus habitantes la prestación de dichos servicios por ser de interés prioritario en la Administración Pública (Dromi, 1991). Por consiguiente, servicio público centra su objetivo como medio para un fin cercano enfocado sólo a la prestación de un servicio, así, Hauriou citado por Gordillo (2013), define servicio público como "un servicio técnico prestado al público de una manera regular y continua para la satisfacción de una necesidad pública y por una organización pública(...)" (p. 285) y para Maldonado (2010) el servicio público es uno de los temas más importantes del Derecho Administrativo, convertido en la razón de ser del Estado Social de Derecho, convirtiéndose en la materialización de éste en pro del bienestar de todos los ciudadanos contratado con la afirmación de Sarmiento (1996): "Actividad administrativa desarrollada por entidades estatales 0 por su delegación, que tiene por finalidad satisfacer necesidades individuales de importancia colectiva, mediante prestaciones materiales en especie, periódicas y sistemáticas" citado en (Efrón, M., p. 9, 2004), así, se esboza un modelo de provisión eficiente en la gestión de los bienes púbicos pero compartido con la intervención de naturaleza pública y de la acción colectiva social.

\section{Origen de los Baños Públicos en Bogotá}

El origen de los baños públicos esta referenciado en el proyecto de Acuerdo 172 de 2013 expedido por el Concejo de Bogotá2, donde citan a "Los egipcios, los griegos y los romanos fueron posiblemente los mentores de los baños públicos. En Atenas existían desde el siglo V a. de C(...)", Asimismo, en Proyecto de acuerdo 219 (2013) se describe el "El baño público para los hombres era el momento ideal para encontrarse con amigos y charlar; era un lugar ideal para filosofar. Famosas son las Termas de Caracalla, un amplio complejo de baños de la Roma imperial, construidas entre 212 y 216 d.C, durante la administración del emperador Caracalla. Las extensas ruinas de estas termas son actualmente una atracción turística importante en la capital italiana" (Parrafo 4).

El servicio de baños públicos es un servicio a cargo del Distrito, cuya finalidad es atender las necesidades fisiológicas que requieren las personas en determinado lugar, especialmente en sitios donde transita un alto número de individuos o donde se realizan espectáculos que aglomeran intensidades de público, o simplemente zonas de afluencia de personas en lugares comerciales y otros donde se concentra población para conseguir lo que necesita. Los empresarios que ofrecen a la comunidad diferente tipo de actividades comerciales, recreativas, industriales y otra clase de servicios, son requeridos por el Estado para que construyan en sus instalaciones suficiente número de baños y atiendan las necesidades de los usuarios. En Bogotá el servicio de baños públicos ha estado a cargo del Distrito a través de entidades públicas como la EDIS 3 , desde su creación hasta su liquidación, y el Instituto Distrital para la protección de la Niñez y la Juventud IDIPRON ${ }^{4}$, entidad que actualmente administra éste servicio.

En la Tabla $\mathrm{N}^{\circ} 1$, se ilustra la evolución del servicio de baños públicos desde 1891, año en el cual se firmó el primer Acuerdo por el Consejo de Bogotá hasta el 2006 cuando se firmó el último Acuerdo relacionado con baños públicos.

${ }^{2}$ Concejales Ponentes: CLARA LUCIA SANDOVAL - NELLY PATRICIA MOSQUERA - MARTHA ORDÓÑEZ - SEVERO ANTONIO CORREA ORLANDO PARADA DÍAZ - ANDRÉS CAMACHO CASADO - FELIPE MANCERA ESTUPIÑAN - JAVIER PALACIO MEJIA

${ }^{3}$ EDIS: Empresa Distrital de Servicios Públicos (1958-1993), antes Empresa Distrital de Aseo

4IDIPRON: Creada en 1967. Responsable del servicio de baños públicos desde 2001 
Tabla N ${ }^{\circ} 1$.

Antecedentes Históricos y Evolución de los Baños Públicos en Bogotá

\begin{tabular}{|c|c|c|c|c|c|}
\hline TIPO & $\mathbf{N}^{\circ}$ & AÑO & TITULO & OBSERVACIÓN GENERAL & OBSERVACIÓN BAÑOS PÚBLICOS \\
\hline Acuerdo & 27 & 1891 & $\begin{array}{l}\begin{array}{l}\text { Aprobatorio de un contrato sobre construcción de } \\
\text { orinales públicos }\end{array} \\
\end{array}$ & $\begin{array}{l}\text { Ordena la construcción de kioscos } \\
\text { y orinales públicos }\end{array}$ & Especifica su estructura \\
\hline Acuerdos & $5 y 7$ & 1910 & Organización del Servicio de higiene de la ciudad & Aspectos sanitarios generales & $\begin{array}{l}\text { Art.6y7 Inspección sanitaria en baños y excusados } \\
\text { públicos }\end{array}$ \\
\hline Acuerdo & 6 & 1922 & Reorganiza los servicios de higiene municipal & Inspección de Higiene y salubridad & Art.11 Inspección Técnica en baños y excusados públicos \\
\hline Acuerdo & 23 & 1933 & $\begin{array}{l}\text { Establece la enseñanza agrícola por medio del } \\
\text { cinematógrafo y se dictan otras providencias }\end{array}$ & $\begin{array}{l}\text { Dotación a los obreros de } \\
\text { alcantarillado y jornales }\end{array}$ & $\begin{array}{l}\text { art. } 5 \text { Alcaldía establecerá un servicio de baños para los } \\
\text { obreros municipales. }\end{array}$ \\
\hline Acuerdo & 21 & 1936 & $\begin{array}{l}\text { Ordena la ejecución de algunas obras, crea el servicio } \\
\text { de buses municipales para niños de los barrios } \\
\text { obreros, da una autorización al Alcalde y ordena dos } \\
\text { traslados }\end{array}$ & $\begin{array}{l}\text { Ejecución de algunas obras en el } \\
\text { Distrito. }\end{array}$ & $\begin{array}{l}\text { ARTICULO 1. La Alcaldía de Bogotá construirá, en } \\
\text { cada uno de los barrios obreros de la } \\
\text { ciudad...servicios colectivos de baños y sanitarios. }\end{array}$ \\
\hline Acuerdo & 21 & 1944 & $\begin{array}{l}\text { Divide el área urbanizable de Bogotá en varias zonas } \\
\text { de destino y se reglamenta cada una de ellas }\end{array}$ & $\begin{array}{l}\text { Reglamentación del área Urbana } \\
\text { de Bogotá }\end{array}$ & $\begin{array}{l}\text { Arts. } 18 \text { y } 19 \text {. Estructura medidas y ventilación de los } \\
\text { brños y retretes de Bogotá }\end{array}$ \\
\hline Acuerdo & 78 & 1946 & Crea el Departamento de Higiene, Salubridad y Aseo & $\begin{array}{l}\text { Implementar medidas que } \\
\text { contribuyan a la salud pública }\end{array}$ & $\begin{array}{l}\text { Art. } 90 \text { literal k) Colaborar con la Secretaría de Obras } \\
\text { Públicas. Proyecto de en el es de baños, servicios } \\
\text { sanitarios públicos... }\end{array}$ \\
\hline Acuerdo & 60 & 1967 & $\begin{array}{l}\text { Por el cual se ordena la construcción de sanitarios } \\
\text { públicos. }\end{array}$ & $\begin{array}{l}\text { El Fondo de Desarrollo Popular } \\
\text { Deportivo y de Cultura y la EDIS, } \\
\text { se vinculan con el objetivo del } \\
\text { Acuerdo. }\end{array}$ & $\begin{array}{l}\text { El Fondo de Desarrollo Popular Deportivo y de Cultura } \\
\text { y la EDIS, construirán y financiarán respectivamente el } \\
\text { servicio de baños públicos. }\end{array}$ \\
\hline Acuerdo & 80 & 1967 & $\begin{array}{l}\text { Por el cual se crea el Instituto Distrital para la } \\
\text { Protección de la Niñez y de la Juventud }\end{array}$ & Creación de IDIPRON & $\begin{array}{l}\text { IDIPRON actualmente (2015) administra los } 37 \text { baños } \\
\text { públicos que existen en Bogotá }\end{array}$ \\
\hline Acuerdo & 18 & 1989 & $\begin{array}{l}\text { Por el cual se expide el Código de Policía para el } \\
\text { Distrito Especial de Bogotá }\end{array}$ & $\begin{array}{l}\text { Artículo } 339^{\circ} \text { - Quien realice } \\
\text { necesidades fisiológicas en vía } \\
\text { pública o lugar público, se hará } \\
\text { acreedor a trabajo en obras de } \\
\text { interés público }\end{array}$ & $\begin{array}{l}\text { La norma ordena sancionar a quien no haga uso del } \\
\text { servicio de baños públicos. }\end{array}$ \\
\hline Acuerdo & 7 & 1993 & $\begin{array}{l}\text { Por el cual se establecen algunas condiciones, para } \\
\text { los contratos relacionados con la construcción de } \\
\text { estacionamientos en el subsuelo del espacio público }\end{array}$ & $\begin{array}{l}\text { Condicionamiento para construir } \\
\text { baños públicos en los } \\
\text { parqueaderos. }\end{array}$ & $\begin{array}{l}\text { Artículo 21.- Todo parqueadero que se haga en la ciudad } \\
\text { para poder funcionar, tendrá obligatoriamente que construir } \\
2 \text { baños públicos al pie de todos sus accesos para } \\
\text { hombres y mujeres y para uso de todos los transeúntes, los } \\
\text { cuales estarán bajo el cuidado del concesionario y por el } \\
\text { cual cobrará una tarifa. }\end{array}$ \\
\hline Acuerdo & 20 & 1995 & $\begin{array}{l}\text { Por el cual se adopta el Código de Construcción del } \\
\text { Distrito Capital de Bogotá, se fijan sus políticas } \\
\text { generales y su alcance, se establecen los } \\
\text { mecanismos para su aplicación, se fijan plazos para } \\
\text { su reglamentación prioritaria y se señalan } \\
\text { mecanismos para su actualización y vigilancia } \\
\end{array}$ & $\begin{array}{l}\text { Baños, lavanderias, cuartos de } \\
\text { aseo y su organización. }\end{array}$ & $\begin{array}{l}\text { Acuerdo que regula las construcciones, incluidas las del } \\
\text { Servicio de Baños Públicos }\end{array}$ \\
\hline Acuerdo & 1 & 1998 & $\begin{array}{l}\text { Por el cual se Reglamenta la Publicidad Exterior } \\
\text { Visual en el Distrito Capital de Santa Fe de Bogotá }\end{array}$ & $\begin{array}{l}\text { Mobiliario urbano para el servicio al } \\
\text { público }\end{array}$ & $\begin{array}{l}\text { Mobiliarios de Amoblamiento Urbano... De Salud e } \\
\text { Higiene: Los baños y objetos recolectores de basura }\end{array}$ \\
\hline Acuerdo & 79 & 2003 & Por el cual se expide el Código de Policía de Bogotá & $\begin{array}{l}\text { Art.25 Num. 10. Utilizar los baños } \\
\text { para satisfacer necesidades } \\
\text { fisiológicas. Nunca hacerlo en sitios } \\
\text { públicos }\end{array}$ & $\begin{array}{l}\text { Parágrafo 1. El Gobierno Distrital garantizará la existencia } \\
\text { de baños públicos en número suficiente para el servicio de } \\
\text { la comunidad. }\end{array}$ \\
\hline Acuerdo & 257 & 2006 & $\begin{array}{l}\text { "Por el cual se dictan normas básicas sobre la } \\
\text { estructura, organización y funcionamiento de los } \\
\text { organismos y de las entidades de Bogotá Distrito } \\
\text { Capital y se expiden otras disposiciones." }\end{array}$ & $\begin{array}{l}\text { IDIPRON se acoge a esta } \\
\text { estructura y se reglamenta su } \\
\text { funcionamiento }\end{array}$ & $\begin{array}{l}\text { Actualmente IDIPRON se acoge al Acuerdo } 257 \text {, en lo } \\
\text { atinente al servicio de baños públicos en Bogotá. }\end{array}$ \\
\hline
\end{tabular}

Fuente: Elaboración Propia con base en documentos de la Alcaldía Mayor de Bogotá (1891-2006), Consulta de la norma - Secretaría General 
No se han obtenido registros históricos que hagan un esbozo detallado de cómo, cuándo y porqué, los baños comenzaron a ser considerados como un servicio público. Tampoco se han encontrado antecedentes orientados a consultar cómo ha sido el desarrollo de dicho servicio y cuál es la finalidad en la prestación del mismo, sin embargo, es posible llegar a una aproximación histórica teniendo en cuenta que a nivel estatal cualquier función pública debe estar sustentada en una ley o decreto que la reglamente, tal como ocurrió con la primera concepción de los baños públicos como un servicio público en el año 1891, cuando se desempeñaba como Alcalde de la ciudad de Bogotá, Higinio Cualla, pues el 3 de agosto de ése año la Administración Distrital para atender la necesidad de la población, especialmente en los lugares más concurridos, por medio del Concejo Municipal de Bogotá expidió el Acuerdo 27 de $1891^{5}$, el cual no presenta datos ni detalla situaciones que lo antecedan, más no describe por qué se suscribió; sin embargo, en el texto de la norma se encuentran características alusivas al contrato de prestación del servicio.

Ahora bien, el referido Acuerdo no fue suscrito por el crecimiento de la población de Bogotá, pues para ese año (1891), los índices de natalidad eran muy bajos en comparación con los índices de mortalidad (192 contra 1067) $)^{6}$, por ejemplo en 1884 Bogotá tenía 95.813 habitantes mientras que en 1898 la población había disminuido a 78.000 (Pavony, 2000). Esta estadística evidencia que en la época el génesis de los baños públicos obedeció a otro tipo de necesidades de la capital. Todo Estado en su organización gubernamental incluye la Administración Pública como ente fundamental para organizar adecuadamente los servicios públicos que toda sociedad requiere para atender a sus necesidades primarias. Arnoletto (2007), argumenta que los bienes públicos son útiles para la ciudadanía cuando presta uno 0 varios servicios y que a su vez, estos siempre deben estar disponibles para el uso de todas las personas.

A medida que los países experimentan un crecimiento económico pueden cumplir los objetivos del gasto público en educación, vivienda, transporte y otras áreas, asimismo las necesidades de los asociados van cambiando y los gobiernos proceden a revisar sus normas, hacen modificaciones a los entes encargados de asegurar el bienestar de todos los residentes del país y propugnan porque las personas se sientan satisfechas con los servicios que el Estado les ofrece, pues está obligado por la Constitución Política, Art 365 (Congreso de la República, 1991) señalando que "Los servicios públicos estarán

\footnotetext{
5 "Aprobatorio De Un Contrato Sobre Construcción De Orinales Públicos". 6 Tanto el índice de natalidad (192) como el de mortalidad (1.067) se calculan sobre 1.000 habitantes.
}

sometidos al régimen jurídico que fije la ley, podrán ser prestados por el Estado, directa 0 indirectamente, por comunidades organizadas, o por particulares. En todo caso, el Estado mantendrá la regulación, el control y la vigilancia de dichos servicios (...)". Además, servicios como el agua y la energía eléctrica en el caso de Colombia están presentes en los planes de desarrollo de los gobiernos, porque las coberturas son muy débiles y no garantizan el acceso general. Tal es el caso del Servicio de Baños Públicos en Bogotá.

En la historia Urbana de Bogotá, se presenta un enfoque sustancialmente diferente de la concepción presente de los baños públicos; el origen de estos se inicia a orillas del río Bogotá o lo más cerca posible a las orillas, debido a que a esos sitios concurrían personas a tomar baños completos y pasar ratos de esparcimiento (Pavony, 2000), este fenómeno se daba, puesto que evitaba a la población el habitual baño en albercas y patios o solares de las casas. Al estimarse la aceptación de este servicio por el grueso de la población, al final de la primera década del siglo XX empezaron a ser considerados como parte del "equipamiento urbano" (Pavony, 2000). El servicio de baños públicos como se expuso en la Tabla N¹, volvió a ser parte de la agenda distrital cuando se aprobaron los Acuerdos 21 de 1936 el cual facultaba a la Alcaldía de Bogotá para construir baños públicos en cada uno de los barrios obreros de la ciudad y el Acuerdo 78 de 1946.

Años después el Concejo de Bogotá reorganizó mediante el Acuerdo $N^{\circ} 75$ de 1960 la Empresa Distrital de Servicios Públicos "EDIS" asignándole nuevas funciones entre las cuales estaba la de administrar los servicios públicos. Con el Acuerdo 60 de 1967, siendo Alcalde Mayor de la ciudad de Bogotá, el doctor Virgilio Barco Vargas, el servicio de baños públicos pasó a estar a cargo de la EDIS, entidad que también tenía a cargo la recolección, transporte y disposición final de los residuos sólidos, el barrido de las calles, la limpieza de muros y monumentos públicos; así como la gestión administrativa de 18 plazas de mercado minorista, con las que contaba la ciudad de Bogotá en esa época Bacca, (2013). Así permaneció la EDIS a cargo del servicio de baños públicos hasta 1993, año en el cual por medio del Acuerdo Distrital $N^{\circ} 41$, el Concejo de Bogotá determinó su liquidación y supresión. Sin embargo, en 1994 se crea la Unidad Ejecutiva de Servicios Públicos UESP7, a través del Decreto Distrital $\mathrm{N}^{\circ} 782$ como una entidad técnica a la cual se le asignan las funciones de servicios de barrido, recolección, disposición de residuos sólidos, cementerios, hornos crematorios, plazas de mercado y galerías comerciales.

\footnotetext{
${ }^{7}$ La Unidad ejecutiva de Servicios Públicos UESP, cambia su razón social en el año 2006 por Unidad Administrativa Especial de Servicios Públicos UAESP (Acuerdo 257 de 2006)
} 
Dicho Decreto no hace mención del servicio de Baños Públicos de Bogotá y no existen antecedentes hasta el 2001 cuando el IDIPRON asume la administración de dicho servicio.

\section{Instituto Distrital Para La Protección De La Niñez Y La Juventud "IDIPRON"}

Durante la administración del Alcalde Mayor de Bogotá, doctor Virgilio Barco, se crea el Instituto Distrital para la Protección de la Niñez y la Juventud "IDIPRON" mediante el Acuerdo 80 de $1967^{8}$ del Concejo de Bogotá, entrando a funcionar a partir de 1970 como un establecimiento público perteneciente al sector descentralizado del Distrito Capital con personería Jurídica propia, patrimonio propio y autonomía administrativa (Concepto 35 de 2002 IDIPRON)9 . Su prioridad es atender a los "niños de la calle comúnmente llamados gamines" (Resolución 20 de 1986 IDIPRON) $)^{10}$, integrando profesionales especializados en el tratamiento de la problemática callejera, generando programas de atención integral educativo y terapéutico a favor de la población infantil y juvenil en condiciones de indigencia. Para el cumplimiento de sus propósitos institucionales IDIPRON define la Misión "Desde un proyecto pedagógico de inclusión social el IDIPRON promueve la garantía del goce efectivo de los derechos de Niños, Niñas, Adolescentes y Jóvenes con dignidad humana, respeto por la pluralidad, la diversidad y la libertad, en un marco de progresividad priorizando las acciones de política pública en aquellos en alto grado de vulnerabilidad social" (IDIPRON, 2014). Por tanto, el programa de Baños Públicos incluye la supervisión a los puntos de los Baños Públicos, el buen trato a los usuarios y ejercer una permanente comunicación con los responsables de los Convenios; por consiguiente, el Proyecto 724 genera oportunidades en la población vulnerable, tomando como referente las mujeres madres cabeza de familia para que obtengan ingresos por medio de laborales con diversos proyectos y convenios suscritos por la entidad. Así, el Proyecto 724 vincula las mujeres madres en la "Operación de los Baños Públicos", buscando que estas mujeres posteriormente puedan estar en capacidad de constituir microempresas 0 alcanzar mejores objetivos laborales que les faciliten el sustento y una condición digna para vivir en comunidad.

\footnotetext{
${ }^{8}$ Por el cual se crea el Instituto Distrital para la Protección de la Niñez y de la Juventud. El Concejo del Distrito Especial de Bogotá

${ }^{9}$ Por medio de la cual se expide el Estatuto Orgánico para el Instituto Distrital para la Protección de la Niñez y de la Juventud IDIPRON

10 Concepto sobre la naturaleza jurídica del "IDIPRON". Radicación: 12002-11237
}

Las condiciones para tener acceso a los beneficios están definidas por la institución y corresponden a: provenir de barrios pobres, ser jefes de hogar, no tener quien las sustente económicamente, vivir en inquilinatos 0 viviendas subnormales, de igual manera debe tratarse de personas que han sido maltratadas (IDIPRON, 2010)

De otro modo, para generar ingresos IDIPRON acude a la modalidad de la operación de Baños Públicos del Distrito, que el Instituto gestiona mediante convenios con Transmilenio, la Secretaría General de Bogotá, el Consejo Superior de la Judicatura y el Departamento Administrativo del Espacio Público (Ver Tabla 2) , estas madres, según el portal de Internet de IDIPRON "Además de velar por la higiene del servicio sanitario, han empezado a distribuir sus productos elaborados con material reciclado" (IDIPRON 2014). En la meta del proyecto 724 estaba proyectado contratar anualmente un mínimo de 85 madres cabeza de familia en el programa de Baños Públicos, en el 2013 se incluyeron 106 madres que se rotaban en turnos laborales, para el mes de agosto de 2014, la meta mínima de vinculación ya se había cumplido, pues en ese mes el Instituto ya contaba con 86 colaboradoras por contrato de Prestación de Servicios con un ingreso mensual de $\$ 1^{\prime} 149.500$. El monto del contrato varía dependiendo de la duración del mismo y cada madre asume las prestaciones sociales y el valor de la estampilla del ICA por trabajar con el Distrito ${ }^{11}$. El Componente De Baños Públicos - Proyecto 724 especifica la ubicación de los puntos de distribución en un total de 24 zonas de los Baños Públicos en Bogotá (ver cuadro 3 ).
11 Contrato por prestación de servicios a madres cabeza de familia colaboradoras del programa de baños públicos suministrado por IDIPRON 
BAÑOS PÚBLICOS EN BOGOTÁ: UNA APROXIMACIÓN AL PROBLEMA SOCIAL EN LA PROVISIÓN DE BIENES PÚBLICOS

Ruben Darío Diaz Mateus - William Fernando Rojas Henao

Tabla N². Convenios Baños Públicos

\begin{tabular}{|l|l|r|r|l|}
\hline \multicolumn{1}{|c|}{ CONVENIO } & \multicolumn{1}{|c|}{ CONCESIÓN } & \multicolumn{1}{c|}{ DESDE } & \multicolumn{1}{c|}{ HASTA } & \multicolumn{1}{c|}{$\begin{array}{c}\text { PRORROGA } \\
\text { AUTOMATICA }\end{array}$} \\
\hline Convenio N $\mathrm{N}^{\circ}$ 93/07/2007 & \multicolumn{1}{|c|}{ TRANSMILENIO } & $24 / 09 / 2007$ & $23 / 09 / 2015$ & CADA 6 MESES \\
\hline Convenio N 2212100/20/2010 & \multicolumn{1}{|c|}{ SECRETARIA GENERAL } & $22 / 01 / 2010$ & $21 / 01 / 2018$ & CADA 4 AÑOS \\
\hline Convenio N 05 & $\begin{array}{l}\text { CONSEJO SUPERIOR DE LA } \\
\text { JUDICATURA }\end{array}$ & & & \\
\hline Convenio DADEP & $\begin{array}{l}\text { DEPARTAMENTO ADMINISTRATIVO DEL } \\
\text { ESPACIO PÚBLICO }\end{array}$ & $10 / 10 / 2013$ & $09 / 10 / 2018$ & CADA 5 AÑOS \\
\hline
\end{tabular}

Fuente: Elaboración Propia con Base en Información Primaria IDIPRON Junio 2014

Tabla N 3. Distribución de los Baños Públicos en Bogotá

\begin{tabular}{|l|l|l|l|}
\hline Transmilenio & Cades-Supercades & Consejo superior Jud & Administrados \\
\hline Portal 170 & Suba & Tribunales & Las Flores \\
\hline Portal Suba: Plataforma 1 y 2 & Américas & Juzgados Paloquemao & Carrera 68 Con Calle 13 \\
\hline Portal 80: Plataforma 1 y 2 & Bosa & Fiscalía Carrera 10 & Carrera 6 con calle 12 \\
\hline Portal Dorado & 20 Julio & Juzagados Nemquetaba & Plazoleta de la ETB \\
\hline Portal Sur: Plataformas 1 y 2 & Movilidad & & \\
\hline Portal 20 de Julio: Plataforma y Peatonal & & & \\
\hline Portal Bicentenario & & & \\
\hline Estación Ricaurte & & & \\
\hline
\end{tabular}

Fuente: Elaboración propia con base en Información Primaria IDIPRON 2014

\section{METODOLOGÍA:}

El Método básico de la investigación está relacionado con el método descriptivo apoyado en información cualitativa en la percepción de los usuarios del servicio de baños públicos, el cual se aproxima a un escenario de bajo control experimental riguroso de las variables pero con el objetivo de generar imaginarios en la gestión de los baños públicos en Bogotá y la influencia de la institucionalidad en la garantía de derechos colectivos dignos para las personas interactivas con las dinámicas de la ciudad. El instrumentos de recopilación de datos aplicado se denomina muestreo aleatorio simple, para ello se calculó el tamaño de muestra, dado que el objeto del estudio fue determinar la proporción de usuarios de los baños públicos en el Portal 170 con una población de usuarios 25863 por ser un punto de mayor movilidad en la ciudad de Bogotá así, se parte base que estadísticamente:

$$
n=\frac{\left(z^{2} P Q\right) / \varepsilon^{2}}{1+\frac{z^{2} P Q}{N \varepsilon^{2}}}
$$

Donde,
N: Población de 25.863 personas que usan los baños públicos del portal 170 .

Z : Constante que depende del grado de confianza, en éste caso 1.96 para un $95 \%$ de confianza. Esta es la probabilidad que el intervalo de confianza contenga el verdadero parámetro que se desea estimar.

P : Proporción estimada de usuarios de baños públicos en el portal $170=50 \%$ ó 0.5

Q : Proporción estimada complemento $=50 \%$ ó 0.5

$\varepsilon$ : Porcentaje máximo de error admisible en la estimación $=10 \%$. Este valor no es otra cosa que la cantidad de error máximo absoluto que se puede tolerar en las estimaciones muestrales. Teóricamente se define como la distancia entre el estimador y el verdadero parámetro poblacional. Para el procesamiento de los datos se llevó a cabo un análisis descriptivo y exploratorio de cada variable.

n : Tamaño de muestra, 96 usuarios a encuestar. Se establece como muestra 96 usuarios de los baños públicos del Portal 170, con una confianza del $95 \%$ y un error máximo del $10 \%$. Posteriormente, se define 
una muestra de 26 madres colaboradoras en la Prestación del Servicio de Baños Públicos en Bogotá para cruzar la información de la demanda con la oferta en la prestación de servicios públicos, con una confianza del $95 \%$ y un error máximo del $15 \%$ de la siguiente manera:

$$
n=\frac{\left(z^{2} P Q\right) / \varepsilon^{2}}{1+\frac{z^{2} P Q}{N \varepsilon^{2}}}
$$

Donde,

$\mathrm{N}$ : Población de 65 madres cabeza de familia, colaboradoras en la prestación del servicio de baños públicos en Bogotá

n : Tamaño de muestra 26 madres a encuestar.

$\mathbf{Z}$ : Constante que depende del grado de confianza, en éste caso 1.96 para un $95 \%$ de confianza. Esta es la probabilidad de que el intervalo de confianza contenga el verdadero parámetro que se desea estimar.

P : Proporción estimada de madres cabeza de familia, colaboradoras en la prestación del servicio de baños públicos en Bogotá $=50 \%$ ó 0.5
$\mathbf{Q}$ : Proporción estimada complemento $=50 \%$ ó 0.5

$\varepsilon$ : Porcentaje máximo de error admisible en la estimación $=15 \%$. Este valor no es otra cosa que la cantidad de error máximo absoluto que se puede tolerar en las estimaciones muestrales. Teóricamente se define como la distancia entre el estimador y el verdadero parámetro poblacional. Para el procesamiento de los datos se llevó a cabo un análisis descriptivo y exploratorio de cada variable.

\section{RESULTADOS:}

El análisis del proceso metodológico realizado con los usuarios de baños públicos en el Portal Norte en la localidad de Usaquén, se evidencia que tan solo el $29,17 \%$ de la población pertenece a esta localidad, por lo cual, se puede afirmarse que más del $70 \%$ de los habitantes de la ciudad, cuando tienen una necesidad fisiológica, hacen uso y se encuentran fuera de su localidad de residencia, dentro de este grupo sobresalen de localidades: Kennedy, bosa y Teusaquillo con un porcentaje de participación de $43.38 \%$ (ver Figura 4).

Figura 4. Usuarios del Baño Público del Portal 170 por Localidad

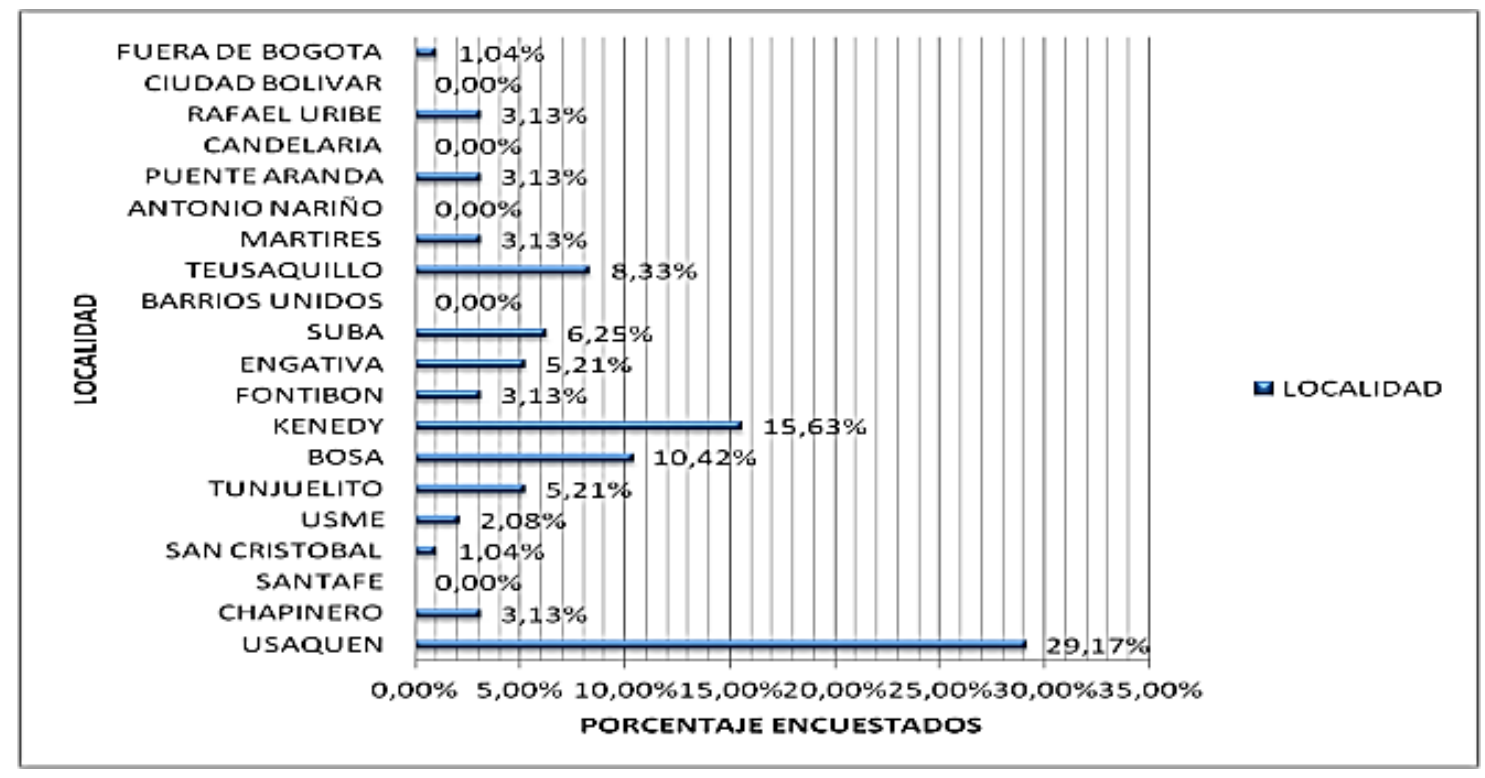

Fuente: Elaboración Propia con base en encuesta aplicada a usuarios. 
Por otra parte, el $89.59 \%$ del total encuestado consideran que es una tarea bastante difícil encontrar un Baño Público en la ciudad (ver Figura 5).

Figura $\mathbf{N}^{\circ} 5$ ¿Cómo encontrar un baño público en Bogotá?

Figura $\mathbf{N}^{\circ} 6$ ¿Presencia de los Baño Públicos en Bogotá?

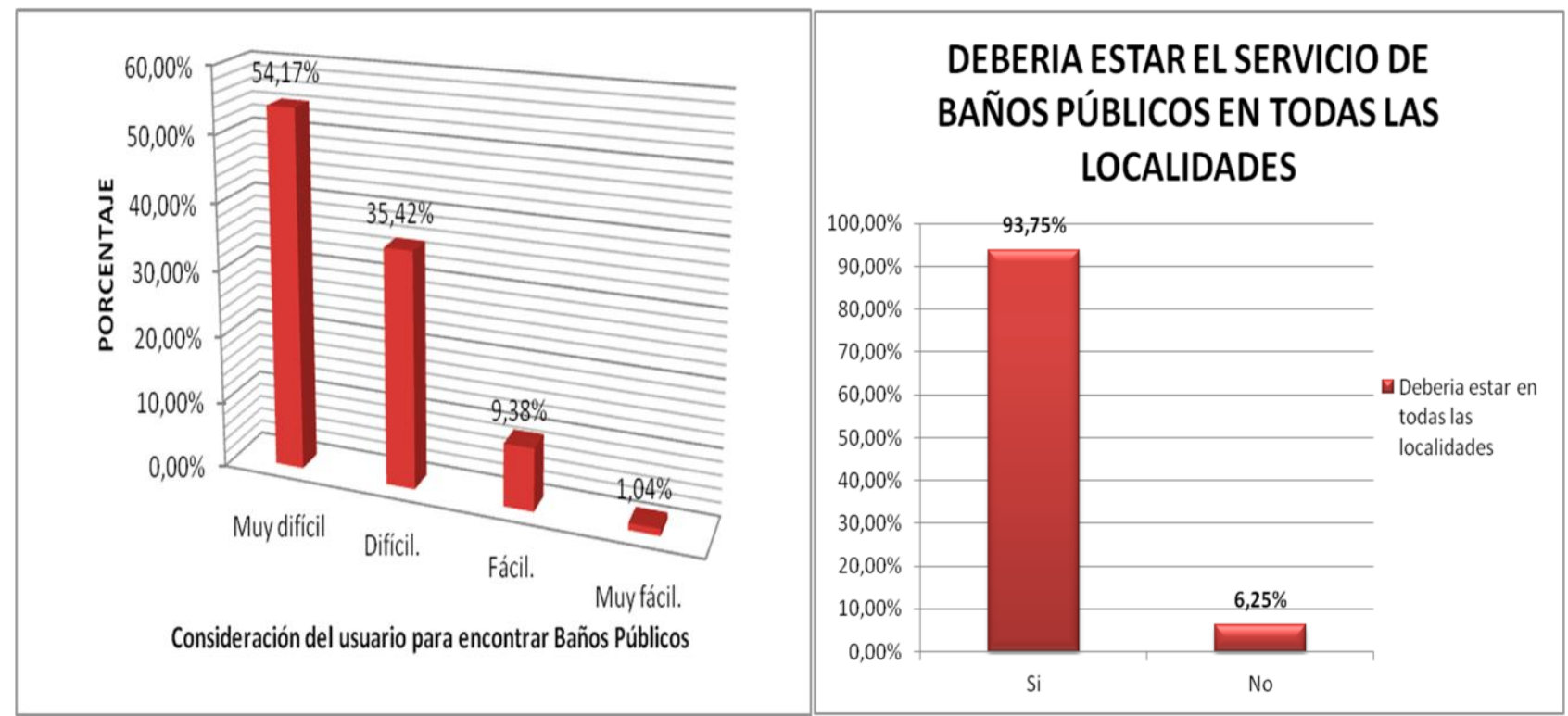

Fuente: Elaboración Propia con base en Instrumento de Investigación.

Figura $N^{\circ} 7$ : Perfil Socioeconómico

Motivo por el cual el $93.75 \%$ de la población consideró que estos Baños Públicos deberían estar ubicados en todas las localidades de la ciudad y no tan solo en las 12 localidades mencionadas en el Proyecto de Acuerdo 278 de 2012 descrito en la presente investigación (Ver Figura 6), a pesar que el Código de Policía de Bogotá menciona que el Distrito garantizará la cobertura del servicio a la totalidad de la población de Bogotá.

Desde otra perspectiva, a pesar que este servicio está dirigido a todos los habitantes de la Ciudad, se evidencia una baja demanda del servicio por personas de estrato 6 contrario al perfil del usuario de este servicio: $47,92 \%$ corresponde a personas del estrato tres; asimismo, la mitad de los usuarios tienen ingresos de dos salarios mínimos o inferiores y su nivel educativo, representando $26,04 \%$ para estudios Técnico, 46,88\% para Profesional en formación $46,88 \%$ (Ver figuras 7, 8 y 9).

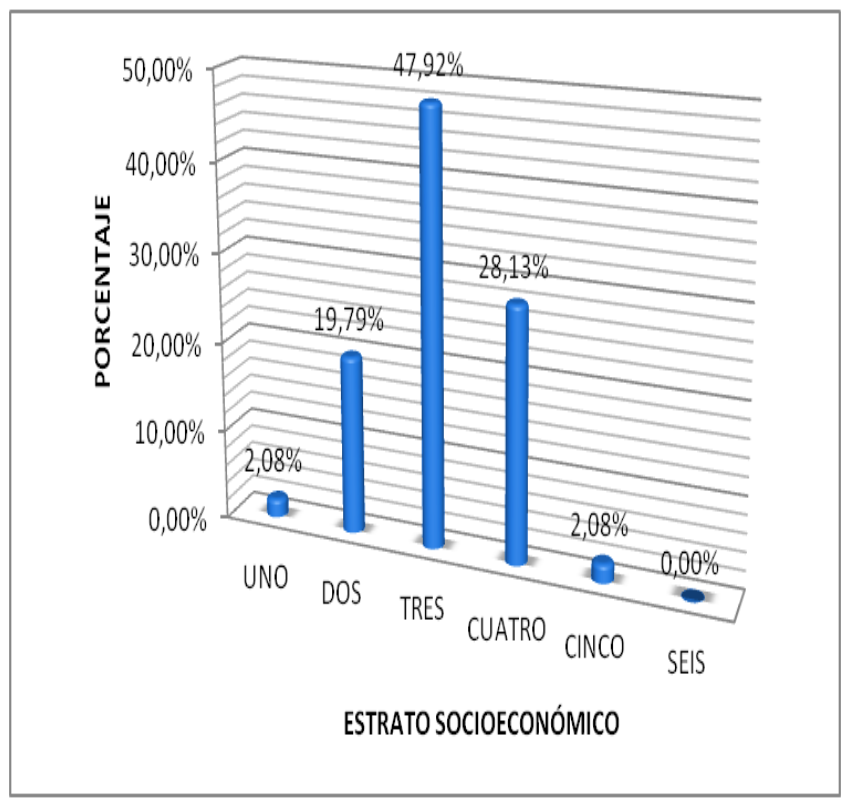

Fuente: Elaboración Propia con base en Instrumento de Investigación 
Figura $\mathrm{N}^{\circ}$ 10. Conoce

CONOCEEL USUARIOIDPRON

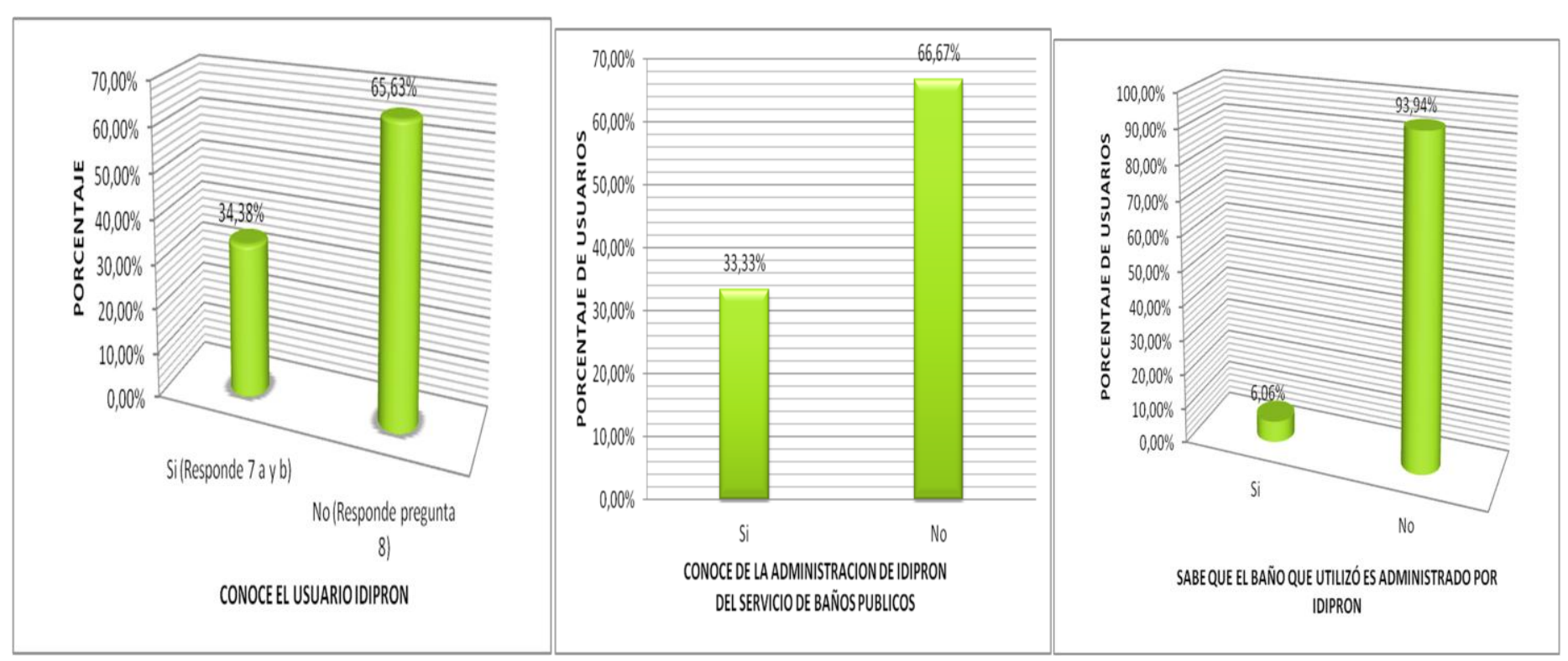

Figura $\mathrm{N}^{\circ} 11$. Sabe de la

Administración del servicio
Figura $\mathbf{N}^{\circ}$ 12. Sabe que el Baño que utilizo es administrado por IDIPRON

Fuente: Elaboración Propia con base en Instrumento de Investigación

Asimismo, el $86.46 \%$ de los usuarios del servicio de baños públicos acceden esporádicamente (Ver Figura 13), debido a casos de necesidad o extrema urgencia. Cuando las personas no se encuentran cerca de un establecimiento del Distrito que les preste el servicio de baño público, el $68.75 \%$ se ve en la necesidad de acudir a un centro comercial.

Figura $\mathbf{N}^{\circ}$ 10. Frecuencia de uso de servicio

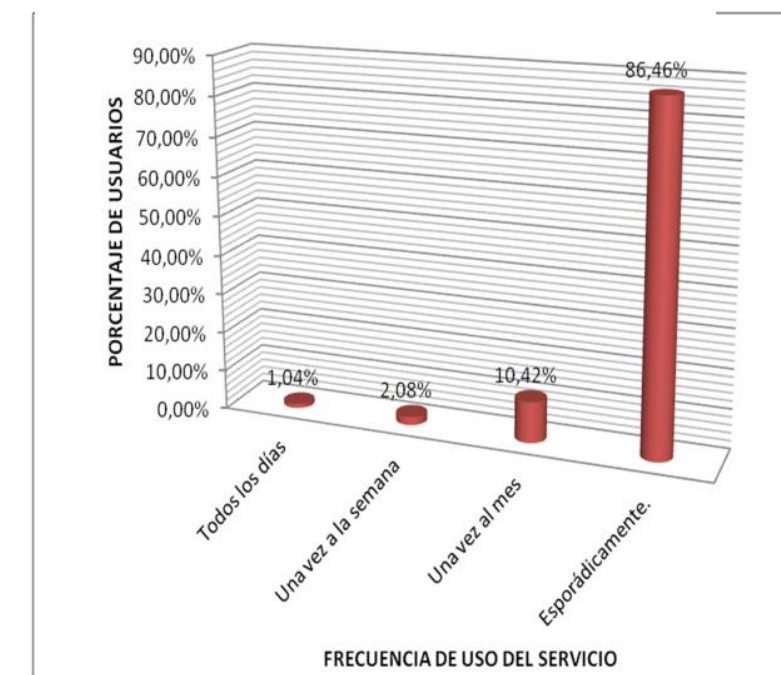

Fuente: Elaboración Propia con base en Instrumento de Investigación
Sin embargo, si no están cerca de alguno, un $18.75 \%$ decide acudir a un establecimiento privado aunque tenga que pagar y consumir algún producto, por tanto, el riesgo de realizar en evento en el espacio público representa un porcentaje de $12.5 \%$ ante la emergencia sanitaria, sin importarle la violación a las disposiciones legales contempladas en el Código de Policía, donde sancionan esta práctica como un hecho que atenta contra la moral y las buenas costumbres de la sociedad ${ }^{12}$ Acuerdo 79 de 2003 (Ver Figura 14).

Figura $\mathbf{N}^{\circ} 10$. Alternativa usada en ausencia

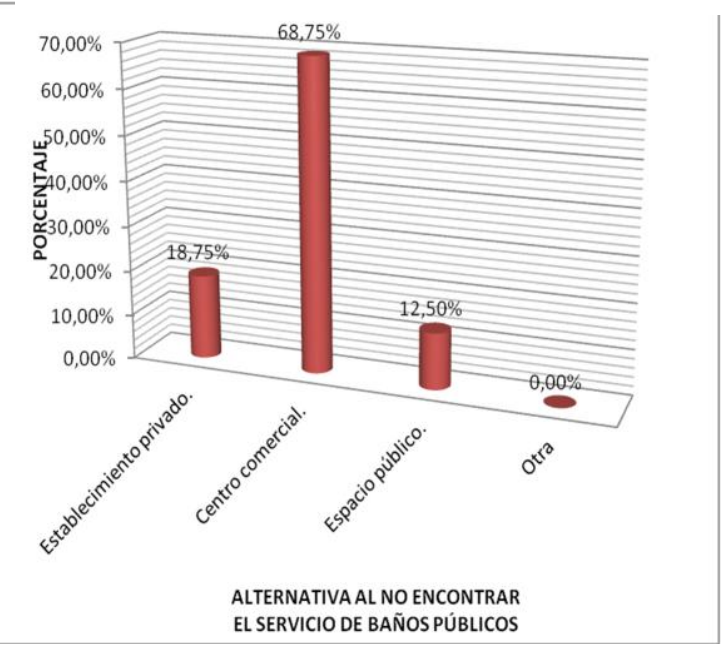

${ }^{12}$ Por el cual se expide el código de policía de Bogotá D.C. 
Ruben Darío Diaz Mateus - William Fernando Rojas Henao

La problemática en la prestación del servicio se centra en las irregularidades y la investigación lo confirma con un $38.55 \%$ como REGULAR O MALO (ver Figura 15); el $40.54 \%$ de los usuarios manifiestan como causa significativa de no uso a la falta de higiene, $21.62 \%$ por la no disponibilidad del servicio, $16.22 \%$ por Inseguros, y un $13.51 \%$ lo consideran costoso, argumentando la necesidad de gratuidad del servicio en contraste con los centros comerciales de la ciudad (ver Figura 16).
No obstante, el $61 \%$ de los usuarios percibe el servicio como BUENO O MUY BUENO y el $48.96 \%$ dice que la atención prestada por las madres cabeza de familia que administran estos baños es BUENA. Del total de la población el $60.42 \%$ dice que el servicio se ajusta apenas a la necesidad de los usuarios (ver Figura 18).
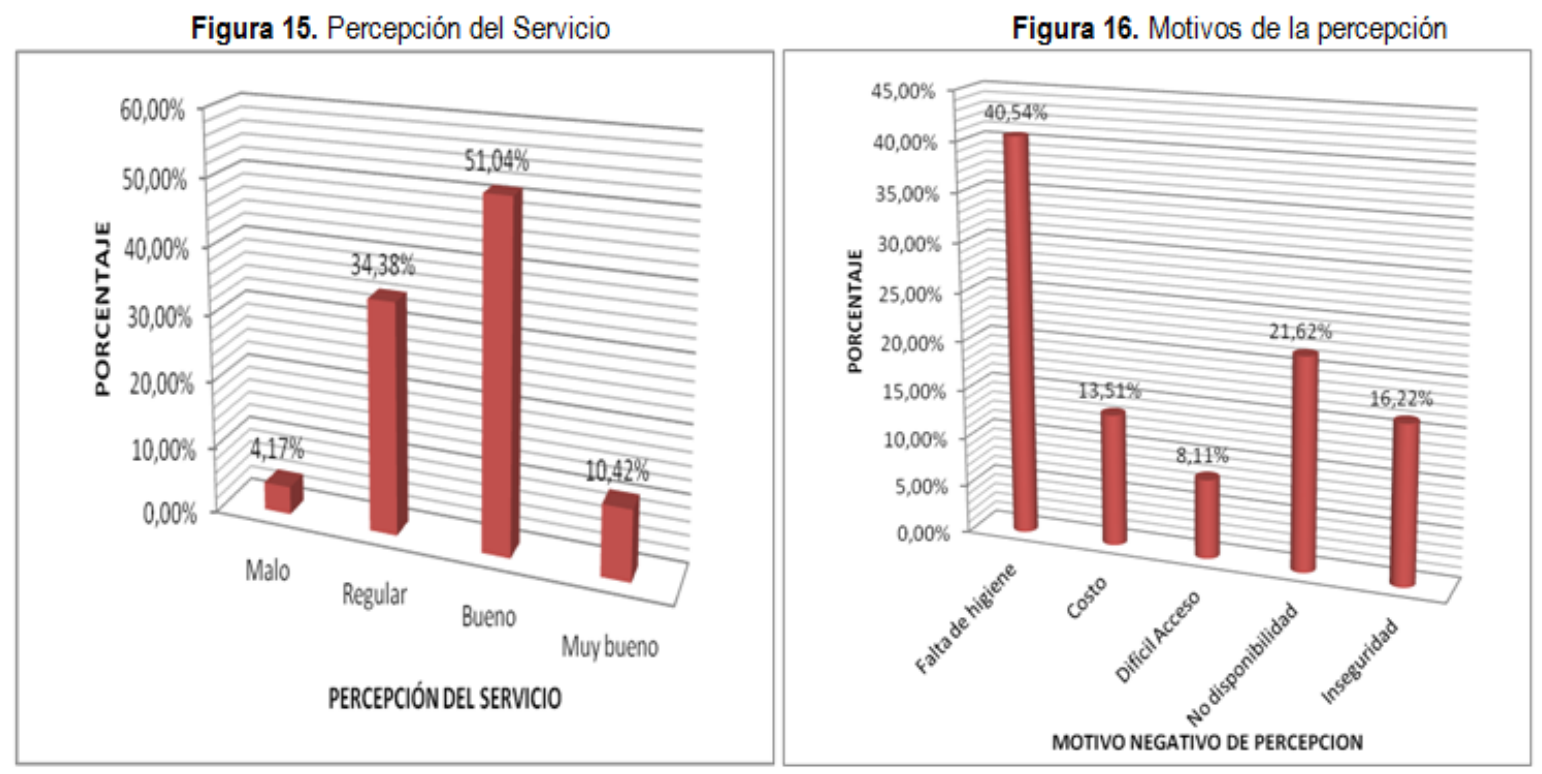

Fuente: Elaboración Propia con base en Instrumento de Investigación

Figura 17. Calificación del Servicio

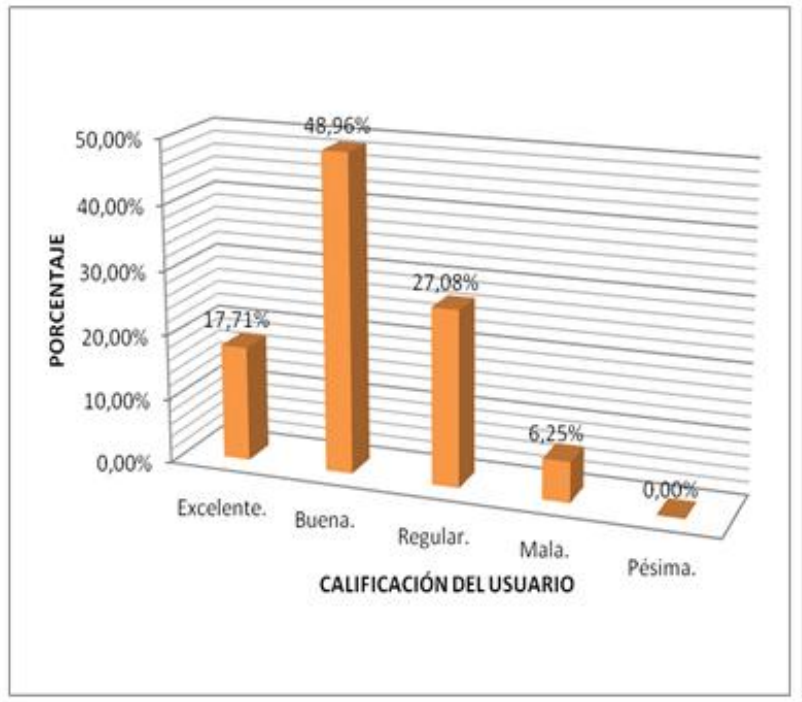

Figura 18. Nivel de Ajuste de las Instalaciones

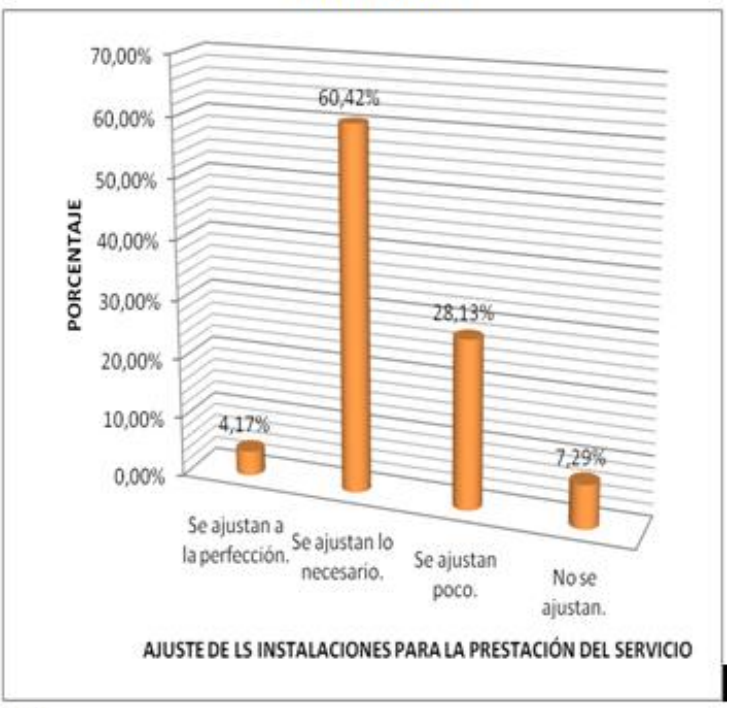

Fuente: Elaboración Propia con base en Instrumento de Investigación 
En el proceso de la segunda muestra desde el lado de oferta y representado por las madres operadoras del servicio de IDIPRON, se halló que oscilan entre 28 y 57 años de edad. En la categoría socioeconómica se evidencia los siguiente: la mayoría de ellas tiene tres hijos, correspondiendo al $30.76 \%$ (ver figura 19).
El origen de residencia está en municipios aledaños a Bogotá en las poblaciones de Soacha, Bosa, Zipaquirá, entre otros con un $26.92 \%$, seguido de la localidad de Kennedy con un $19.23 \%$. Un $53.85 \%$ pertenecen al estrato 2 y el $38.46 \%$ al estrato uno, el nivel de escolaridad de las colaboradoras es básico, es decir, como mínimo han hecho la primaria (ver Figura 21) en condiciones de extrema pobreza, uno de los requisitos exigidos por el IDIPRON (ver Figura 20).

En cuanto al tiempo laborado en IDIPRON, la entidad usa el método de contrato por prestación de servicios, lo que hace que la rotación de personal sea elevada, pues aproximadamente el $73 \%$ de las madres contratadas llevan máximo un año y el $15.38 \%$ lleva más de dos años (ver Figura 22); así el $96.15 \%$ perciben un mismo ingreso, que para el 2014 fue de 1'149.500.

Figura $N^{\circ}$ 19. Edades y Número de Hijos de las Colaboradoras del Programa de Baños

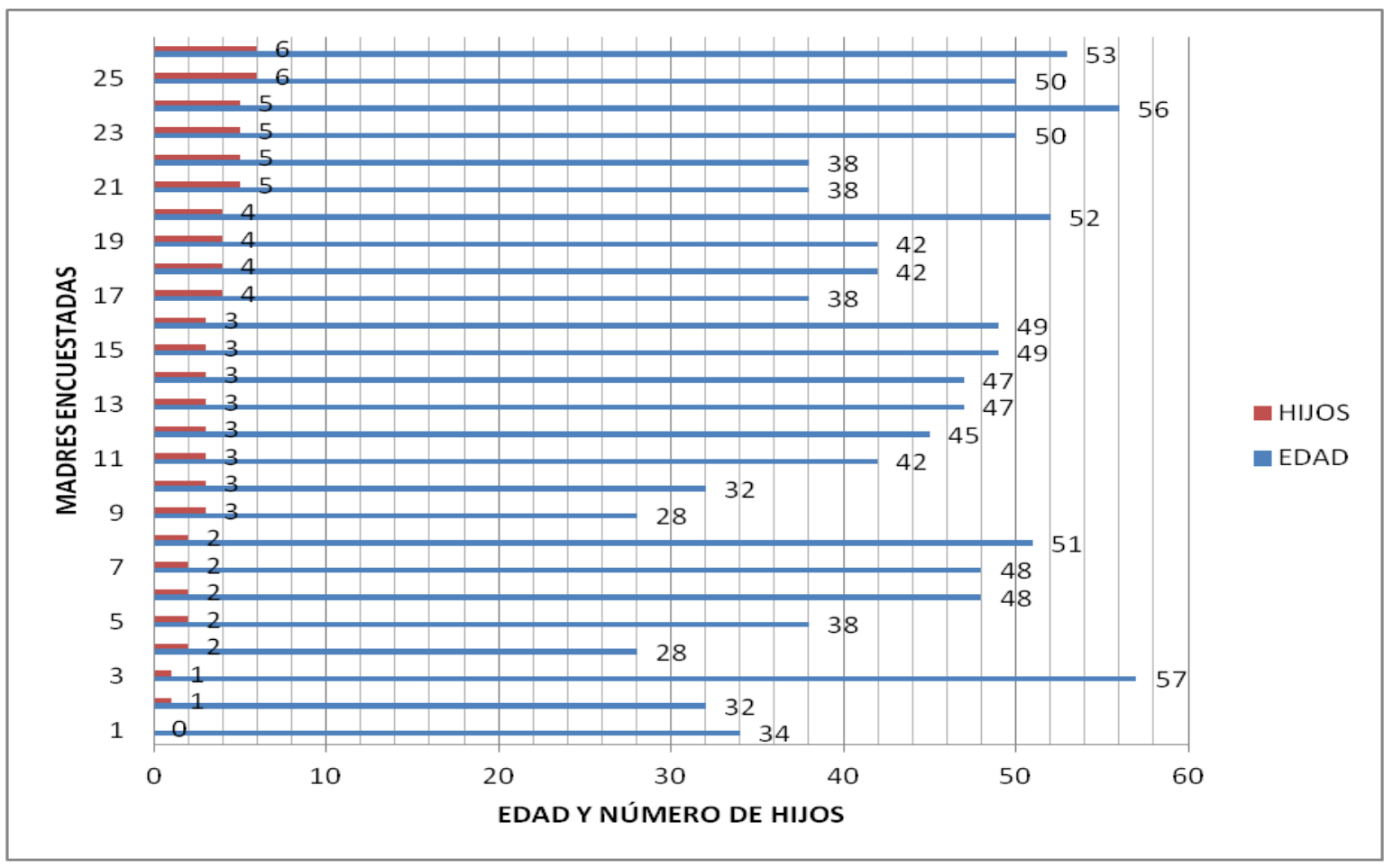

Fuente: Elaboración Propia con base en Instrumento de Investigación 
Ruben Darío Diaz Mateus - William Fernando Rojas Henao

Figura $\mathbf{N}^{\circ}$ 20. Localidad de Residencia de las Colaboradoras del Programa de Baños

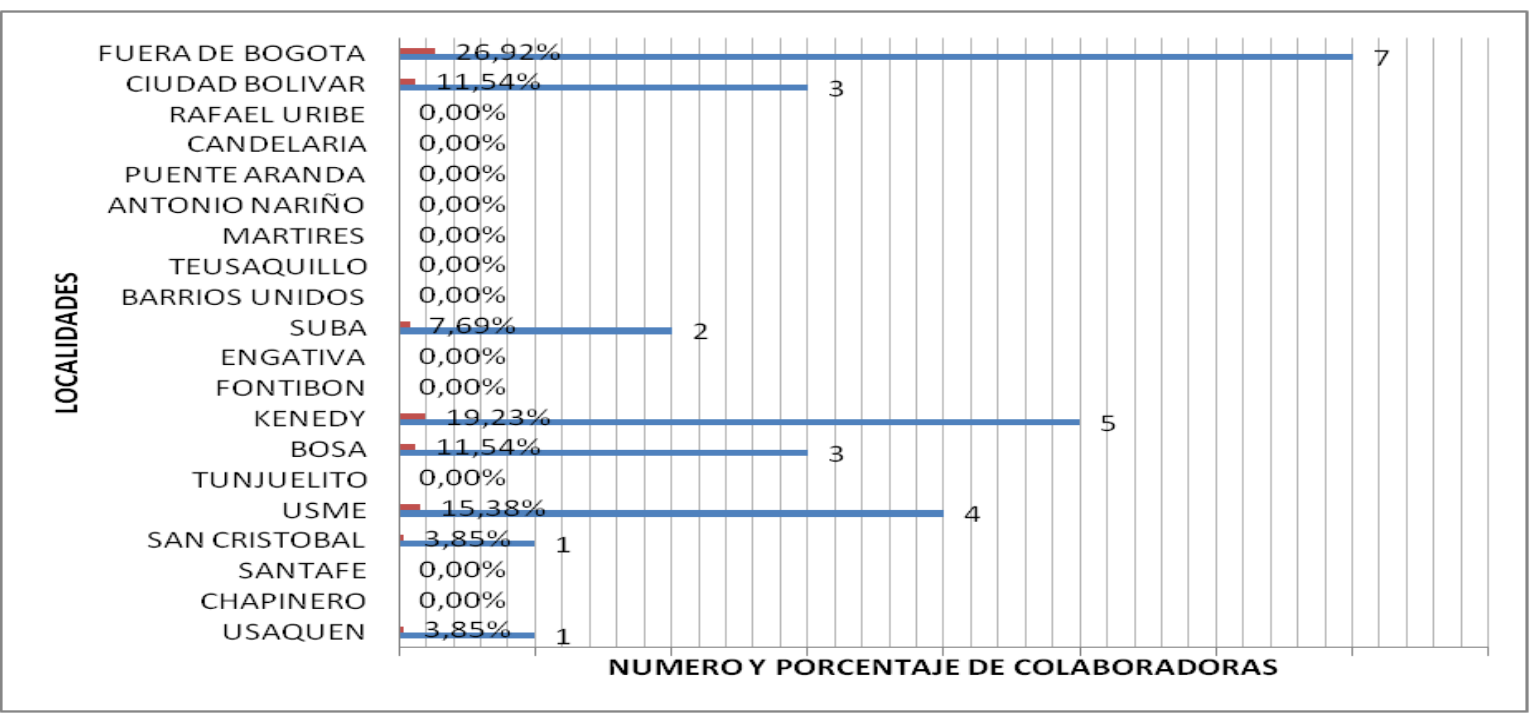

Fuente: Elaboración Propia con base en Instrumento de Investigación

Figura $N^{\circ} 21$. Nivel de Ingresos

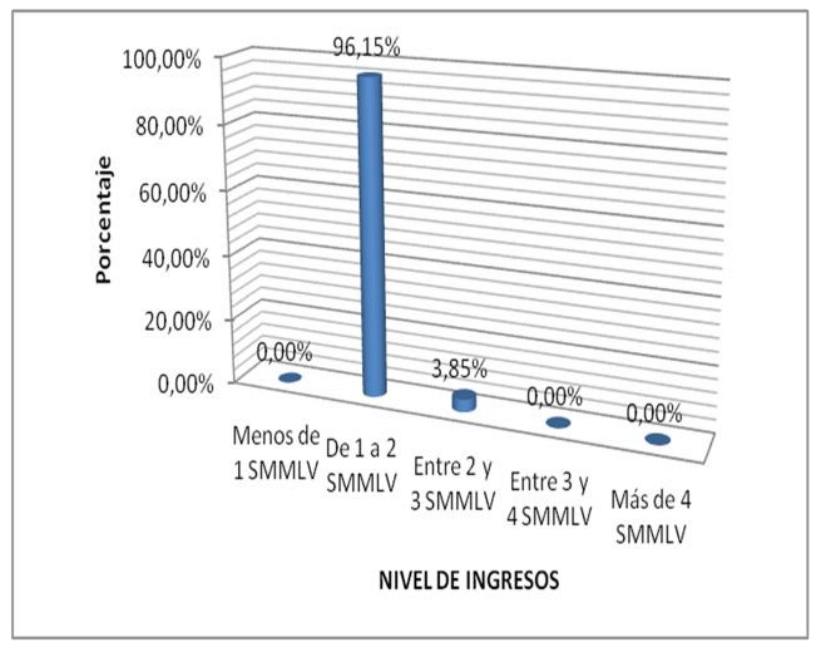

Figura $\mathbf{N}^{\circ}$ 22. Tiempo de Vinculación

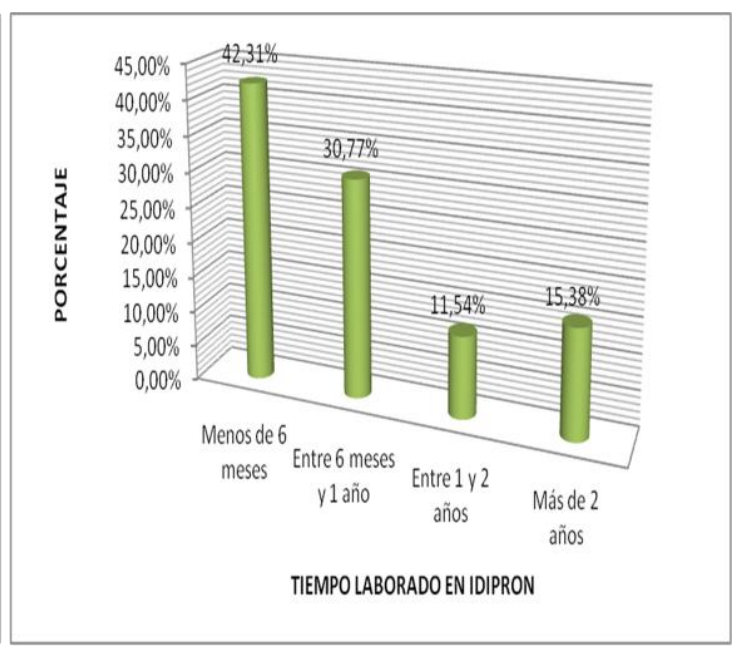

Fuente: Elaboración Propia con base en Instrumento de Investigación

Sin embargo, se percibe que más de la mitad de las madres beneficiarias $(53.85 \%)$ se sienten motivadas con sus ingreso, pues logran mantener su hogar, un $26.92 \%$ pueden ahorrar para cumplir sus sueños y para un $19.23 \%$ simplemente su motivación es que están bien remuneradas con el ingreso mensual que reciben (ver Figura 23); por tal motivo, se afirmar que IDIPRON está cumpliendo uno de los objetivos del proyecto 724 , ya que el $53.85 \%$ de las madres consideran que su calidad de vida ha mejorado a tal punto que el $92.31 \%$ quisieran permanecer en IDIPRON por el resto de su vida, siempre y cuando la entidad renueve sus contratos. Asimismo, destacan el buen trato y respeto por parte de sus directivas (ver Figura 24). 
ISSN: 1794-9920 Enero - Junio 2016

Figura 23. Calidad de Vida

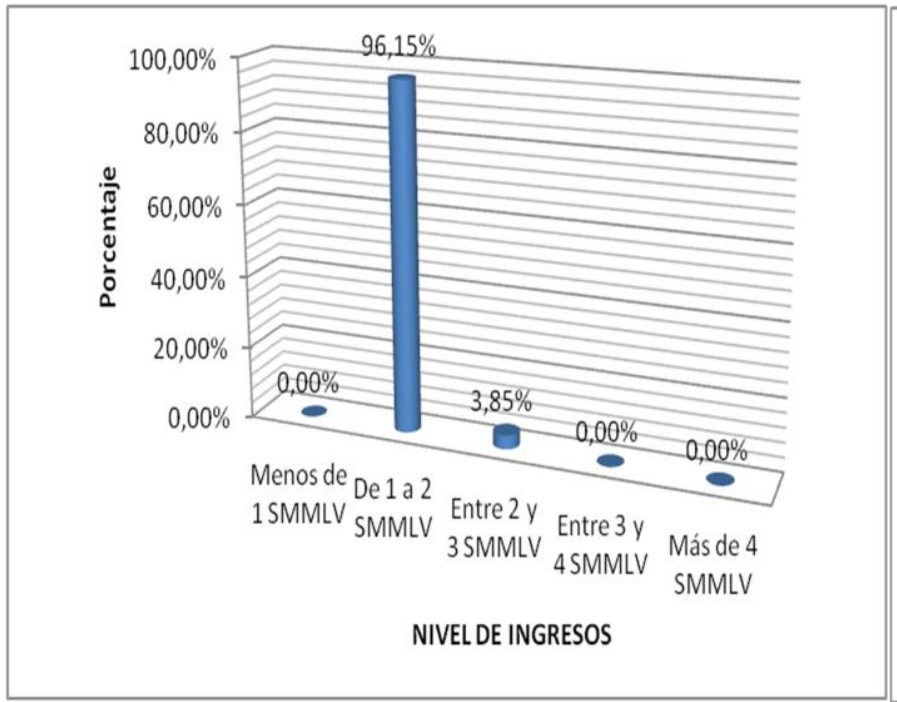

Figura 24. Planes laborales

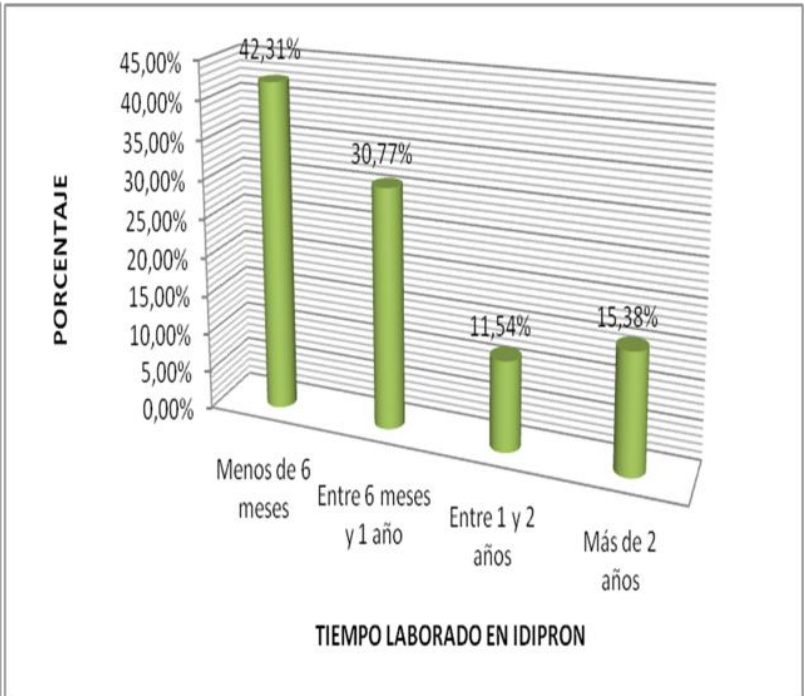

Fuente: Elaboración Propia con base en Instrumento de Investigación

Desde otra óptica se observa un $96.15 \%$ de las madres encuestadas no tienen acceso a programas de capacitación, talleres educativos, eventos culturales, entre otros y están satisfechas con su contrato de trabajo (ver figura 25), por lo tanto, se recomienda revisar investigaciones realizadas respecto a la situación laboral actual del país.

Figura 25. Acceso a Programas Brindados por IDIPRON

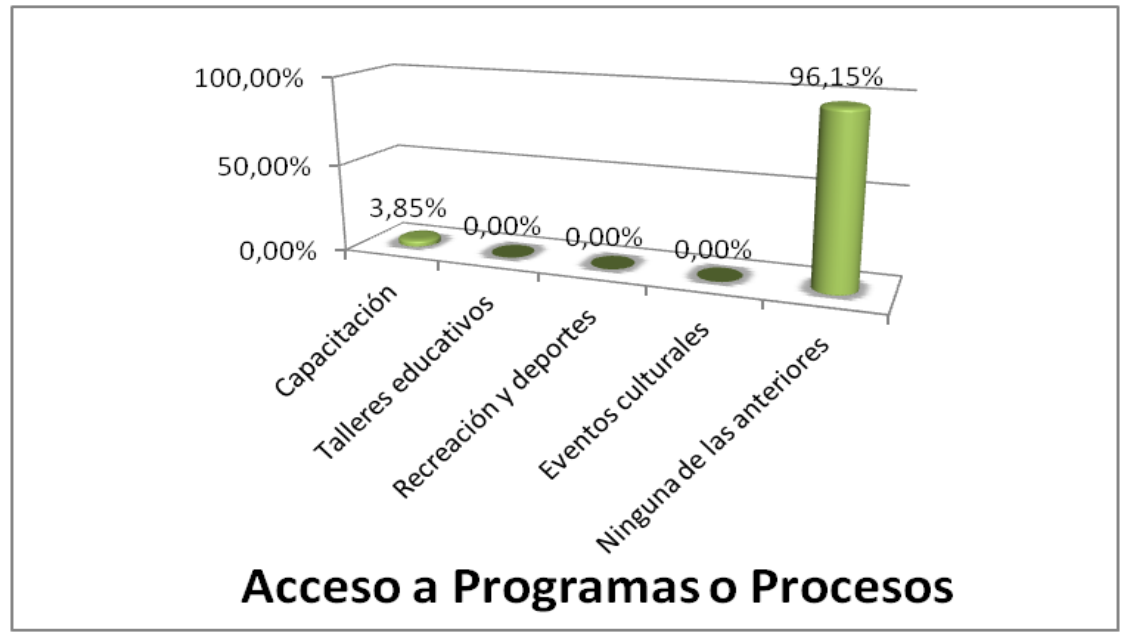

Fuente: Elaboración Propia con base en Instrumento de Investigación 
Ruben Darío Diaz Mateus - William Fernando Rojas Henao

La percepción de las colaboradoras sobre el servicio de baños públicos para satisfacer las necesidades del usuario es en un $88.46 \%$ Adecuado, asimismo el $50 \%$ de las empleadas perciben que para los usuarios el costo del servicio de $\$ 500$ pesos significa un valor permisible de pago, mientras que el $50 \%$ restante de ellas perciben en el usuario una modalidad de pago Gratuito o les parece Costoso (ver Figuras 26 y 27).

Figura 26. Percepción del servicio por parte de los colaboradores

Figura 27. Percepción de las colaboradoras respecto al usuario

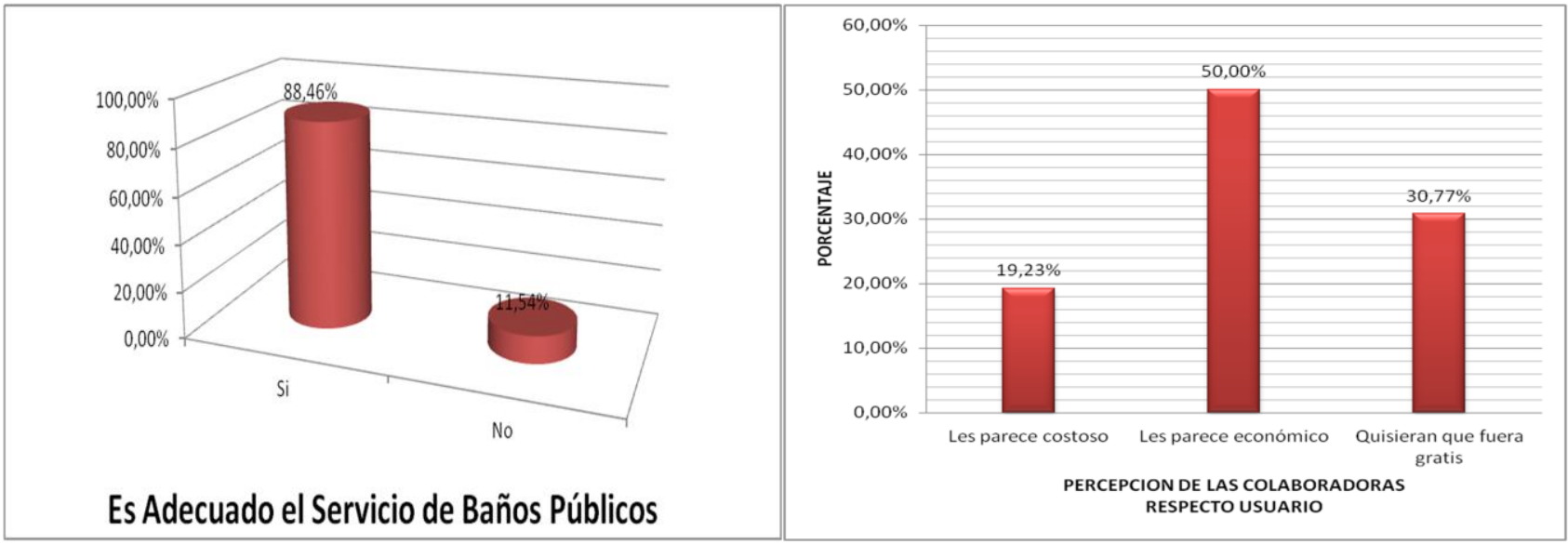

Fuente: Elaboración Propia con base en Instrumento de Investigación

El servicio cuenta con los elementos necesarios para su funcionamiento, según la muestra (prestador del servicio), el $92.31 \%$ considera un buen funcionamiento, el $96.15 \%$ califica el servicio como seguro para los usuarios, aunque se quejan del estado en que dejan los baños después de usarlos Un $61.54 \%$ dicen que los dejan en mal estado, y un $23.08 \%$ en regular estado (ver Figuras 28 y 29 ).

Figura 28. Cuentan con los elementos para la prestación de servicio Figura 29. Cuentan con los elementos para la prestación de servicio
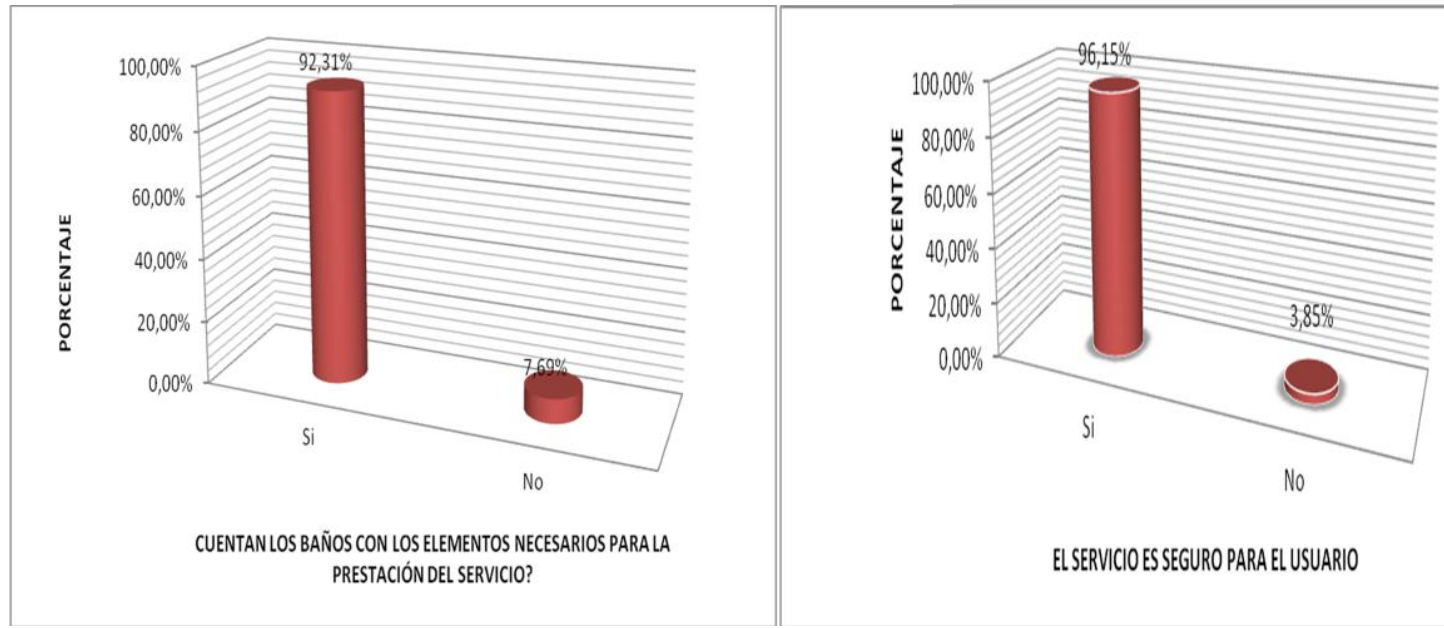

El SERVICIO ESSEGURO PARA El USUARIO

Fuente: Elaboración Propia con base en Instrumento de Investigación 
Por otro lado, el $69.23 \%$ representa el calificativo de mejora en aspectos de mantenimiento y un $7.69 \%$ debe mejorarse en salubridad (ver Figuras 30 y 31 ).
Figura 30. Estado del servicio después de uso

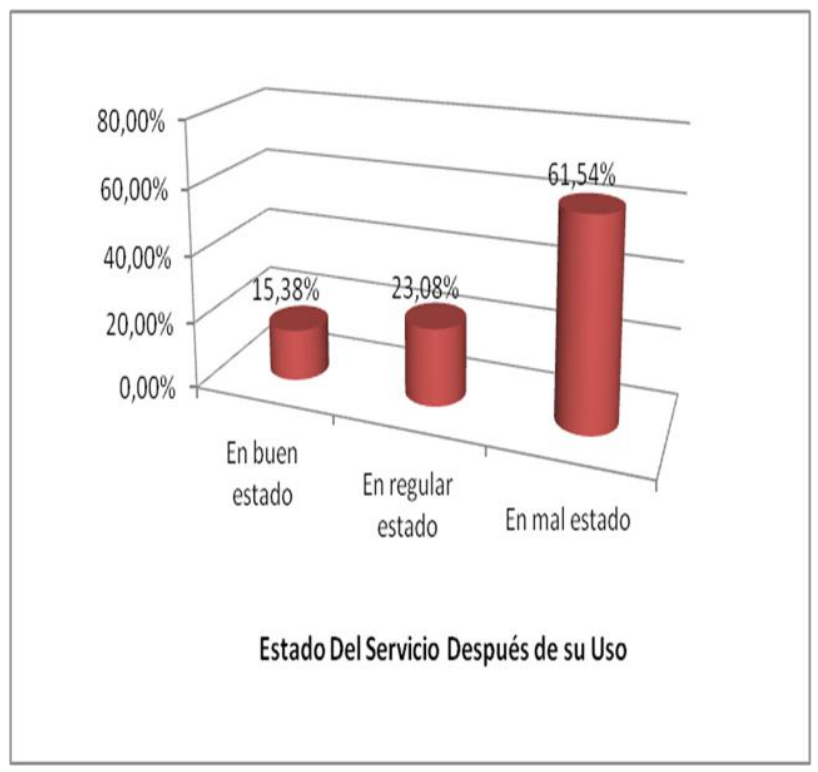

Fuente: Elaboración Propia con base en Instrumento de Investigación

\section{DISCUSIÓN:}

Para el cumplimiento de la Misión, la Visión y los Objetivos Organizacionales, IDIPRON en su estructura orgánica cuenta con tres Subdirecciones: Subdirección Técnica Administrativa y Financiera, Subdirección Técnica de Desarrollo Humano y Subdirección Técnica de Métodos Educativos y Operativos; dentro de las cuales existe la responsabilidad del Proyecto 724, denominado Generación de Ingresos y Oportunidades como Herramienta de Recuperación para Beneficiarios en Fragilidad Social 2013Bogotá Humana donde vincula el convenio "Baños Públicos" y 10 rutas "Mujeres para la vida", por el cual la administración de este servicio se da a partir del 2001 donde el Instituto se responsabiliza de la administración de los baños públicos de Bogotá, mediante la primera concesión otorgada por el Concejo Superior de la Judicatura.

Las diversas situaciones enmarcadas en la ausencia de instalaciones de baños públicos no permiten una óptima relación entre la oferta y la demanda del servicio.
Figura 31. Aspectos a Mejorar en el Servicio

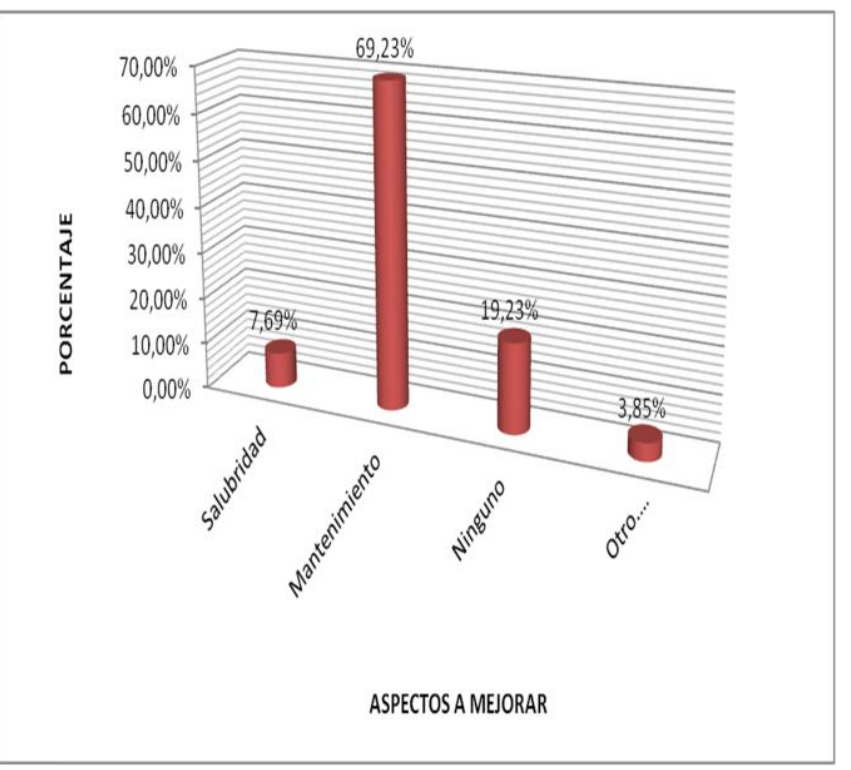


Ruben Darío Diaz Mateus - William Fernando Rojas Henao

Proyecto de Acuerdo 044 de $2013^{14}$ Transmilenio moviliza más de 1'600.000 usuarios al día, entre los que se incluye a mujeres embarazadas, adultos mayores y niños,

Los medios de comunicación, Posada Ángel (2016) sostienen que en la ciudad hay un baño público por cada 80 mil habitantes, donde es muy difícil acceder a un baño público, no solo por la escasez de instalaciones, sino porque algunas veces los usuarios los encuentran cerrados. Esta realidad representa el uso ineficiente de espacios públicos para hacer sus necesidades fisiológicas, convirtiendo dichos lugares en orinales, ocasionando un problema de salubridad que llega inclusive a impedir que algunos ciudadanos transiten por estas áreas. Según el periódico El Tiempo (2014), las personas que más permanecen en la calle como taxistas, lustrabotas, vendedores informales y otros que desarrollan oficios callejeros, son los más afectados ante la deficiencia de este servicio de baños públicos ${ }^{15}$ y según el periodista Jonathan Castro de RCN la Radio, en publicación del 25 de mayo de 2014, la privatización es la principal causa de la desaparición de los baños públicos en Bogotá, pues prácticamente el $90 \%$ de los baños están ubicados en las instalaciones de Transmilenio, los Supercades y en los Cades. Tan solo quedan ocho (8) establecimientos que brindan atención a las emergencias sanitarias de más de 8 millones de personas en Bogotá. Otro factor de gran incidencia está en la mala imagen y preferencias del usuarios, según, el Director de Salud Pública del Distrito Jaime Urrego que: "A la fecha el $27 \%$ de los baños públicos tiene un cumplimiento óptimo y el restante $73 \%$ requiere algún tipo de mejora, por esta situación lamentablemente estos lugares tienden a desaparecer", asimismo, Jimenez (2010), menciona "un anciano que no controle esfínteres... no cuenta con un baño público cerca, y ocurre lo mismo con cualquier ciudadano que tenga un problema estomacal". En consecuencia, el problema de la ausencia del servicio de baños públicos para cubrir las necesidades de la población de Bogotá está presente en la vida cotidiana del ciudadano.

Sin embargo, la concesión y prestación del servicio de baños públicos ofrece una oportunidad, desde la institucionalidad hasta la gestión de un bien público para satisfacer no solo necesidades individuales sino el derecho colectivo a los usuarios y las madres cabeza de familia en pro de la mejorar en la calidad de vida; asimismo, restituye la necesidad de ampliar el servicio, como medida de política pública, para contrarrestar los costos sociales de dinámicas del desarrollo urbano y símbolo histórico de la

\footnotetext{
14 Por el cual se promueve la instalación de baños públicos gratuitos en las instalaciones de Transmilenio de distrito capital y se dictan otras disposiciones proyectos de acuerdo 044-172 de 2013

15 El Tiempo Zona en el Portal El Tiempo en línea Recuperado el 10 de diciembre de 2014 de http://www.eltiempo.com/archivo/documento/CMS14035764
}

ciudad. Finalmente, el usuario percibe una disponibilidad a pagar por internalizar los costos en el usos de los baños públicos pero con una participación de Distrito en el incentivo de ampliar la cobertura del servicio público para mantener una ciudad amable y limpia donde genere beneficios sociales como ciudad histórica, industrial y turística.

\section{CONCLUSIONES:}

En cuanto al modelo de gestión implementado por el Instituto para la Protección de la niñez y la Juventud IDIPRON en la administración del servicio de baños públicos, ha cumplido eficientemente el objetivo en la prestación del servicio a la comunidad, a pesar de tener solo 37 Baños Públicos distribuidos en 20 zonas en Bogotá, especialmente en las Estaciones de Transmilenio, lo que indica que el instituto responde a la exigencia designada por la norma por medio de las concesiones y convenios vigentes en el Programa de Baños Públicos gracias al Proyecto 724, no obstante, contrasta con lo manifestado por los usuarios objeto de estudio, donde el servicio de baños públicos califica de regular en su prestación con un $38,5 \%$ de regular unido a las dificultades en la localización física manifestado por $89,59 \%$ de los usuarios, esta situación causada por higiene, disponibilidad y seguridad del servicio, lo cual refleja la oferta del servicio en todas las localidades.

La evidencia refleja un número de usuarios insatisfechos con el servicio que actualmente ofrece el Estado; dicho servicio lo tildan de insuficiente, antihigiénico e inseguro. Tal inconformismo debería despertar la Administración Distrital y proceder a solucionar cuanto antes la problemática real que actualmente tiene Bogotá. Desde la institucionalidad se han emitido disposiciones legales para que sus habitantes puedan acceder al servicio de baños públicos, el mismo Ente Administrativo no ha invertido en la construcción de instalaciones en las 20 localidades del Distrito Capital para que sean administradas por el mismo gobierno o por entidades privadas. Esto ha hecho que la comunidad en general reclame al gobierno más atención a este servicio, pues muchas zonas transitables de vehículos y peatones se han convertido en "orinales públicos", generando insalubridad y un ambiente de pestilencia, deteriorando la imagen de la ciudad generando un conflicto en el uso de espacios públicos de un $12,5 \%$ de usuarios como resultado de una emergencia humana.

Económicamente se concluye que aunque el costo por utilización del servicio es relativamente económico y no genera pérdidas para el Instituto, el Estado solo ha invertido en unas pocas instalaciones donde se presta el servicio de baños públicos, pero estas son insuficientes 
Congreso de la República. (1991). Constitución Política de Colombia. Bogotá Colombia: Legis.

bien, el presupuesto asignado a IDIPRON para que atienda esta actividad, escasamente alcanza para pagar los salarios de los profesionales que supervisan el servicio y cancelar también los sueldos de las madres cabeza de familia, pero en ningún momento para construir más instalaciones.

Finalmente, IDIPRON incorporadas como colaboradoras a las madres cabeza de hogar en la prestación del servicio de baños públicos proporcionando oportunidades económicas con un ingreso promedio de 1.149 .500 pesos, esto le permite mantener a su hogar y asignar un ahorro del $26,92 \%$ del total de ingreso, mejorando la calidad de vida, sin embargo, esta remuneración no incluye sus prestaciones sociales por ser contratos de prestación de servicios es digna, solucionando parte de la problemática social que vive Bogotá.

\section{REFERENCIAS:}

Argüelles $P, D C,(2013)$. Guía para la presentación de Trabajos científicos bajo el estándar APA en la Universidad EAN. Consulta de la Norma. (1986). Recuperado el 2014, de http://www.alcaldiabogota.gov.co/sisjur/normas/N orma1.jsp?i=20027

Arnoletto, E. J. (2007). Glosario de conceptos políticos. EUMEDNET.

Bacca, R. R. (2013). Historia Institucional de la Alcaldía Mayor de Bogotá, DC Bogotá, grandes definiciones: 1810-1885. Tomo 1. Bogotá: Secretaría General de la Alcaldía Mayor de Bogotá DC y Colegio Mayor Universidad del Rosario, 2011, 254 p. ANUARIO HISTORIA REGIONAL Y DE LAS FRONTERAS, 17(2).

Basavilbaso, B. V. (1950). Derecho Administrativo. Buenos Aires Argentina: T.II.

Bogota, A. d. (2014). Norma 1967. Bogota: http://www.alcaldiabogota.gov.co.

Bogotá, C. d. (2006). Alcaldia de Bogotá. Recuperado el 2014, de Por el cual se Dictan Normas Básicas sobre estructura organización y funcionamiento de los organismos y las entidades de Bogotá, distrito capital, y se dictan otras disposiciones: http://www.alcaldiabogota.gov.co/sisjur/normas/N orma1.jsp?i=22307
De la Encarnación Gabín, M. A. (2009). Administración pública (2da edición ed.). Madrid: Ediciones Paraninfo S.A.

Diez, M. M. (1980). Manual de derecho administrativo. Buenos Aires Argentina: Plus Ultra.

Dromi, R. (1991). Reforma del estado y provatizaciones. Buenos Aires Argentina: Astrea

Efrón, M. H. (2004). La Educación y los fines esenciales del Estado. Deberes, derechos y responsabilidades. Universidad y Servicio Educativo.

El Tiempo (2014). Baños públicos, en abandono. Recuperado el 10 de diciembre de 2014 de http://www.eltiempo.com/archivo/doc umento/CMS-14035764.

González, J. Á. V. (2009). Los bienes públicos globales y regionales: una herramienta para la gestión de la globalización. Cuadernos Unimetanos, (18), 1419.

Gordillo, A. (2013). Teoria general del derecho administrativo. Buenos Aires: FDA.

http://www.idipron.gov.co/index.php/idipron/objetivos-yfunciones. (s.f.).

http://www.idipron.gov.co/index.php/idipron/objetivos-yfunciones. (s.f.).

IDIPRON. (s.f.). Recuperado el 20 de Noviembre de 2014, de http://www.idipron.gov.co/

IDIPRON. (2010). Portafolio de servicios. Bogota: Idipron.

Jimenez, G. V. (2010). No hay baños para tanta gente. Bogota: Boletin virtual concejo como vamos.

Loaiza Gallón, H. (2004). Estado, gobierno y gerencia pública. Bogotá: Universidad Santo Tomás.

Maldonado, T. (2010). Revista Actualidad Juridica. Universidad del Norte, 54.

Pavony, G. M. (2000). Los años del cambio, historia urbana de Bogota 1820-1910. Bogota.

Posada Ángel, F., (2016). El déficit de baños públicos en Bogotá. Recuperado 8 enero del 2016. Disponible en http://www.rcnradio.com/locales/el-deficit-debanos-publicos-en-bogota/ 
Proyecto de acuerdo 219 (2013). "POR EL CUAL SE PROMUEVE LA INSTALACIÓN DE BAÑOS PÚBLICOS GRATUITOS EN LAS ESTACIONES DE TRANSMILENIO DEL DISTRITO CAPITALY SE DICTAN OTRAS DISPOSICIONES. Régimen Legal de Bogotá D.C., Propiedad de la Secretaría General de la Alcaldía Mayor de Bogotá D.C

Rodriguez, R. M. (1980). Aministración Pública Federal en México. Mexico: Instituto de Investigaciones Jurídicas de la UNAM.

Sánchez González, J. J. (2001). La admnistración pública como ciencia. Su objeto y su estudio. Ciudad de México: Plaza y Valdés S.A.

Sarmiento, G., (1996). Temas de introduccion a las instituciones derecho publico. Mendoza : Universidad Nacional de cuyo Citado en Efrón, M. (2004). La educación y los fines esenciales del Estado. Deberes, derechos y responsabilidades. Universidad y servicio educativo. IV COLOQUIO INTERNACIONAL SOBRE GESTION NIVERSITARIA EN AMERICA DEL SUR. Universidad Federal de Santa Catarina.

Secretaria de Planeación. (2013). Secretaria de Planeación. Recuperado el Octubre de 2013, de http://www.sdp.gov.co/portal/page/portal/PortalSD P/InformacionTomaDecisiones/Estadisticas/Reloj DePoblacion

Stiglitz, J. (2000). La economía del sector público. Barcelona. 